Review

\title{
Recent Advances in Nanostructured Conducting Polymers: from Synthesis to Practical Applications
}

\author{
Duong Nguyen Nguyen ${ }^{1}$ and Hyeonseok Yoon ${ }^{1,2, *}$ \\ 1 Department of Polymer Engineering, Graduate School, Chonnam National University, 77 Yongbong-ro, \\ Buk-gu, Gwangju 61186, Korea; nguyendun@gmail.com \\ 2 School of Polymer Science and Engineering, Chonnam National University, 77 Yongbong-ro, Buk-gu, \\ Gwangju 61186, Korea \\ * Correspondence: hyoon@chonnam.ac.kr; Tel.: +82-62-530-1778; Fax: +82-62-530-1779
}

Academic Editor: Frank Wiesbrock

Received: 3 March 2016; Accepted: 25 March 2016; Published: 31 March 2016

\begin{abstract}
Conducting polymers (CPs) have been widely studied to realize advanced technologies in various areas such as chemical and biosensors, catalysts, photovoltaic cells, batteries, supercapacitors, and others. In particular, hybridization of CPs with inorganic species has allowed the production of promising functional materials with improved performance in various applications. Consequently, many important studies on CPs have been carried out over the last decade, and numerous researchers remain attracted to CPs from a technological perspective. In this review, we provide a theoretical classification of fabrication techniques and a brief summary of the most recent developments in synthesis methods. We evaluate the efficacy and benefits of these methods for the preparation of pure $\mathrm{CP}$ nanomaterials and nanohybrids, presenting the newest trends from around the world with 205 references, most of which are from the last three years. Furthermore, we also evaluate the effects of various factors on the structures and properties of $\mathrm{CP}$ nanomaterials, citing a large variety of publications.
\end{abstract}

Keywords: conducting polymers; nanomaterials; nanohybrids; synthesis methods; applications

\section{Introduction}

Over the past decade, there has been significant progress in fabricating nanostructured materials with unique properties. In particular, the topic of intrinsically conducting polymers (CPs) has seen an explosion in the number of published papers, which have been very useful for both fundamental research and potential applications. CPs are polymeric materials that display high conductivities, good electrochemical activity, unique optical properties, and biocompatibility. Because of these interesting properties, CPs have received special attention as promising candidates in many areas of nanoscience and nanotechnology.

CPs, also known as conjugated polymers or "synthetic metals," are polymers with highly $\pi$-conjugated polymeric chains. Alan MacDiarmid, Hideki Shirakawa, and Alan Heeger were awarded the Nobel Prize in Chemistry in 2000 for the discovery of inherent CPs. Up to now, a variety of CPs (e.g., polyaniline (PANI), polypyrrole (PPy), polythiophene (PT), poly(3,4-ethylenedioxythiophene) (PEDOT), and other PT derivatives) have been developed (see Figure 1). While there has been continuous progress in the development of $\mathrm{CPs}$, there has also been increasing interest in $\mathrm{CP}$ nanohybrids. Hybrid nanomaterials, the combination of CPs with different types of materials, such as metals, carbonaceous materials, and inorganic compounds, have been studied most intensively. Such nanohybrids have proven to be attractive for a wide variety of applications, from organic electronics to energy storage, solar cells, and sensors. As can be seen in Figure 2, the number of studies regarding $\mathrm{CP}$ nanomaterials has rapidly increased over the last decade. 


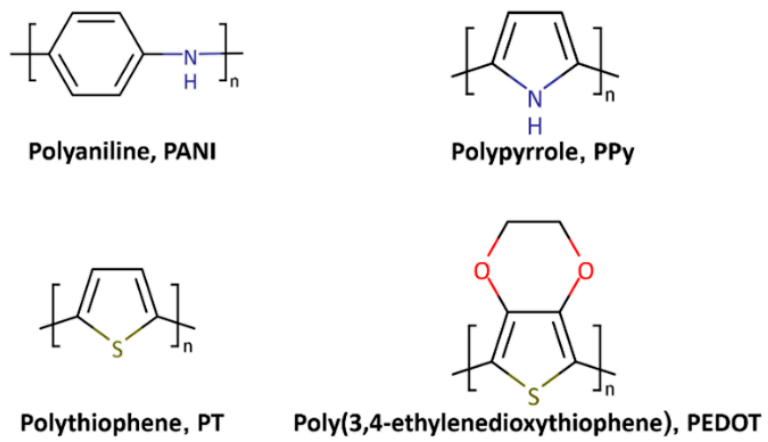

Figure 1. Chemical structures of representative conducting polymers (CPs).

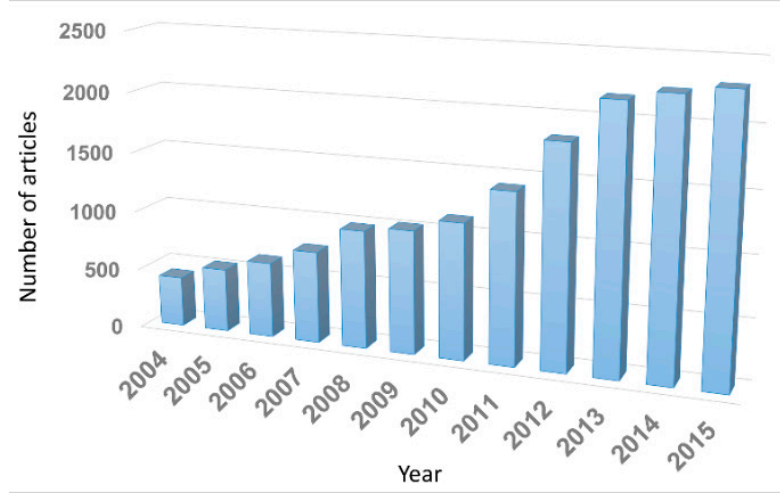

Figure 2. The number of articles published on $\mathrm{CP}$ nanomaterials over the last decade. Data from the ISI Web of Knowledge database.

From the very early years of studying CPs, there have been numerous efforts to hybridize CPs with inorganic species. Metals $(\mathrm{Ag}, \mathrm{Au}$, and $\mathrm{Pd})$, metal oxides $\left(\mathrm{NiO}, \mathrm{Cu}_{2} \mathrm{O}, \mathrm{CuO}, \mathrm{TiO}_{2}, \mathrm{WO}_{3}, \mathrm{ZnO}\right.$, $\mathrm{Fe}_{2} \mathrm{O}_{3}, \mathrm{Fe}_{3} \mathrm{O}_{4}, \mathrm{MnO}_{2}, \mathrm{SnO}_{2}, \mathrm{~V}_{2} \mathrm{O}_{5}$, and $\left.\mathrm{RuO}_{2}\right)$, and chalcogenides ( $\mathrm{Bi}_{2} \mathrm{~S}_{3}, \mathrm{CdSe}, \mathrm{CdS}$, and $\mathrm{CdTe}$ ) have been explored. Recently, carbon nanomaterials (graphene, graphene oxide, and nanotubes) have been frequently employed. This significant investment in development is due to the recognition that nanostructured CPs can play a key role in applications such as Li-ion batteries and supercapacitors (fast electrolyte diffusion), solar cells (effective exciton dissociation), sensors (enhanced sensitivity), and electrochromics (fast response times). In this review article, we first classify traditional synthesis routes for CPs, as well as for hybrid nanomaterials, and present a new standard for classification. From this point of view, we then discuss recent developments in synthesis approaches that have improved conventional methods. Finally, various selected applications have been reported in order to demonstrate the merits of CPs. The key difference between our work and previously published studies $[1-8]$ is that we provide a brief scheme of the synthesis processes for CP nanomaterials, including the mechanism of polymerization, key rules of synthesis, and environments of reactions (e.g., solid, liquid, gas) instead of focusing on the details of one-dimensional (1D) nanostructures [2,3], electrochemical synthesis [5], or sensor applications [1,4,6,8]. This approach creates a unified view of the advantages and disadvantages of each method, thereby enabling the significant features to be better understood and, hopefully, to anticipate new synthesis routes for $\mathrm{CP}$ nanohybrids.

As will be shown later, different synthesis approaches can be conveniently categorized based on three particular aspects: (i) the oxidizing agent or synthetic mechanism, (ii) the template used in the synthesis reaction; and (iii) the order of addition of each component. In this review, we discuss various procedures for fabricating CP-only nanomaterials, as well as CP-based nanohybrids (binary and ternary systems), which are the root of hybrid nanomaterials. 


\section{Overview and Classification of Synthesis Methods}

\subsection{Polymerization Mechanism}

CPs are usually synthesized via oxidative coupling of monomers. For polymerization, the first step is the oxidation of the monomer, which results in the formation of a radical cation, which then reacts with another monomer or radical cation, forming a dimer. Hence, an obvious classification is the initiation process of polymerization. The three general initiation routes are chemical, electrochemical, and photo-induced oxidation, each having its own advantages and disadvantages (Figure 3). In the first route, chemical oxidants (such as ferric chloride or ammonium persulfate) are applied to oxidize the monomer. In the second route, the monomers are oxidized electrochemically, and in the third route, light is required to oxidize the monomer with a photoinitiator. A partial summary of these techniques is shown in Table 1.

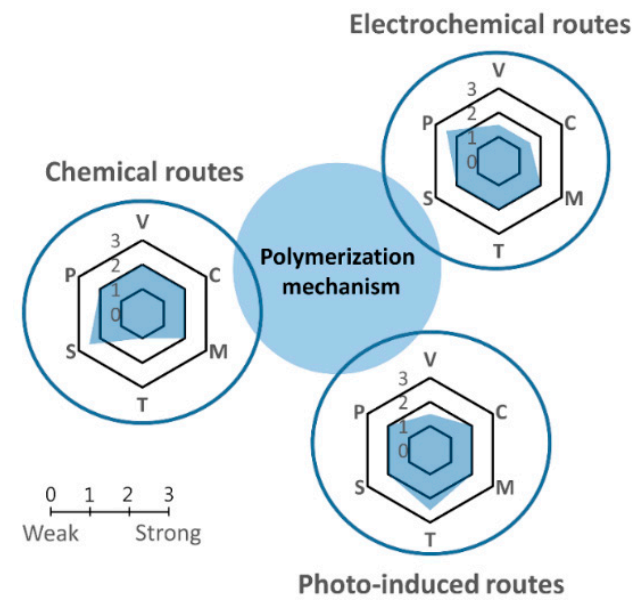

Figure 3. Schematic comparing the chemical, electrochemical, and photopolymerization mechanisms. Each method has been evaluated in term of variables (V), in which a low value means there are many key variables in the synthesis process; cost effectiveness (C), in which a low value corresponds to high cost; morphology control (M); time of reaction (T); scalability (S); and the resulting purity (P) of the materials.

Table 1. Polymerization routes employed to obtain conducting polymers (CPs).

\begin{tabular}{lll}
\hline \multicolumn{1}{c}{ Route } & \multicolumn{1}{c}{ Details } & Ref. \\
\hline Chemical polymerization & $\begin{array}{l}\text { Requires an oxidizing agent to synthesize the polymer. The } \\
\text { morphology of the polymer can be controlled by varying the } \\
\text { parameters of the process, such as monomer/oxidizing agent } \\
\text { concentration, temperature, pH, and reaction time. }\end{array}$ & [9-14] \\
\hline Electrochemical polymerization & $\begin{array}{l}\text { An oxidizing agent is not required for this route, which is an } \\
\text { efficient approach for depositing CPs on substrates. Some } \\
\text { monomers are theoretically not electropolymerizable. } \\
\text { Furthermore, it is difficult to scale up this process. A high } \\
\text { oxidation potential may lead to over oxidation of the polymer. }\end{array}$ & [13,15-19] \\
\hline Photo-polymerization & $\begin{array}{l}\text { Illumination is needed for polymerization. This route was } \\
\text { developed to solve the over oxidation problem of the } \\
\text { electrochemical method. The process can be well controlled } \\
\text { simply by turning the light on or off. }\end{array}$ & [20-24] \\
\hline
\end{tabular}

Chemical synthesis methods involve either condensation polymerization (step-growth mechanism) or addition polymerization (chain-growth mechanism). The main advantage of chemical synthesis is that it not only provides various possible routes to synthesize different $\mathrm{CPs}$, it also permits the large-scale production of these materials, which is currently impossible with electrochemical 
synthesis. Furthermore, chemical synthesis methods have more options in terms of covalent modification of the $\mathrm{CP}$ backbone.

Electrochemical synthesis is a relatively straightforward synthetic method for fabricating CPs. The conductivity of CPs allows them to be electrochemically polymerized. In general, electrochemical polymerization is employed using a three-electrode system (working, counter, and reference electrodes) in a solution comprising a monomer, an electrolyte, and appropriate additives. A number of crucial factors must be considered, including the electrolyte, deposition time/method (continuous versus pulsed) and applied potential. Each of these parameters has an effect on film morphology, conductivity, and mechanical properties, which directly impact the utility of the material for many applications.

The significant differences between chemical and electrochemical methods have been investigated by many researchers. One difference is that very thin CP films (approximately $20 \mathrm{~nm}$ in thickness) can be produced using electrochemical polymerization, whereas powders or very thick films are typically produced using the chemical technique [25]. However, this idea is being challenged. Much effort has been expended on experimental research to overcome this difference, and at the moment, the chemical route can generate thin $\mathrm{CP}$ films via modification of the type and concentration of the oxidizing agent. Although chemical oxidative polymerization can also be applied, the electrochemical route is still preferable for thin CP films because employing an appropriate electrical potential allows the production of high-quality films with the desired thickness [26]. Some drawbacks of the electrochemical method are the relatively poor reproducibility of bulk CPs and the fact that it is quite difficult to remove the grown film from the electrode surface. Most CPs can be synthesized by chemical polymerization, but electrochemical synthesis is limited to those designs in which the monomer can be oxidized via a potential to form reactive radical ion intermediates for polymerization; several standard CPs (i.e., PPy, PT, PANI, PEDOT) can be fabricated both chemically and electrochemically. To date, owing to the chemical diversity of the studied monomers, a general scheme for the electrochemical route cannot be provided. Several reports have made direct comparison of chemical and electrochemical polymerization methods for the same monomers $[27,28]$, which interestingly show that the electrical conductivities of CPs produced electrochemically were higher than those of CPs produced via chemical polymerization. Another work by Gorey et al. showed that the polymerization time for the electrochemical approach is more rapid than that using chemical methods (a few minutes versus a few hours), whereas chemical growth can provide more homogeneous morphologies than the electrochemical route [29].

Photopolymerization (or photoinitiation) is another approach by which monomers can be polymerized by exposure to ultraviolet (UV) light, visible light, laser-generating radicals (photochemical reaction), or holes (photoelectrochemical reaction). Common examples of photopolymerization can be divided into two main categories: (i) direct photopolymerization and (ii) photosensitizer-mediated polymerization. Direct photopolymerization proceeds by absorption of the energy of illumination and then decomposition of the monomers into radicals, which is similar to free radical polymerization. However, it should be noted that CPs cannot be achieved by direct photopolymerization because they have a more positive oxidation peak potential than the redox potential of the photosensitizers [21]. On the other hand, in the photosensitizer-mediated polymerization, the energy transfer from the light occurs via the photosensitizer in order to form the corresponding excited states. In photochemical polymerization, photosensitizers can be used as photocatalysts (e.g., ruthenium complexes, silver nitrate, camphorquinone, and ketones). As compared to the conventional chemical route, photochemical polymerization is more advantageous because the radical is formed through hydrogen abstraction by irradiation, which is generally more efficient than direct fragmentation via a thermal reaction. From a thermodynamic viewpoint, this approach can resolve the problem of large activation barriers for the reaction, which is the limitation of chemical polymerization. As a consequence, the initiation rate can be very fast and well controlled by simply turning the illumination source on or off. In addition, this process provides better control over the shape, size, and physical properties of $\mathrm{CP}$ nanomaterials by tuning the source of the initiator, 
light intensity, and temperature. For photoelectrochemical polymerization, the photosensitizer is a dye-sensitized semiconductor (e.g., metal oxides such as $\mathrm{TiO}_{2}, \mathrm{ZnO}$, and $\mathrm{WO}_{3}$; chalcogenides such as $\mathrm{CdS}, \mathrm{CdSe}$, and GaAs) or simply a dye. This approach was developed in order to solve the problems of electrochemical polymerization. One can see that in some cases, such as in infiltration of CPs into oxides (e.g., $\mathrm{TiO}_{2}, \mathrm{SnO}, \mathrm{W}_{2} \mathrm{O}_{5}$, and $\mathrm{ZnO}$ ), the electrochemical route (i.e., electrodeposition) is often hindered by the low conductivity of the inorganic matrix. Consequently, high potentials must be applied, causing irreversible oxidation (an over-oxidative state) of the electrogenerated CP. Photoelectrochemical polymerization can overcome this issue because illumination of the semiconductor electrode employs band-gap irradiation and improves the electrical conductivity via photoconductivity. The mechanism of photoelectrochemical polymerization can be described as follows: when the semiconductor photosensitizer is illuminated, electrons from the valence band are stimulated to the conduction band. These electrons are drained into an external circuit, leaving holes in the solution. When the photogenerated holes react with a particular monomer, oxidation begins and initiates polymerization. A primary aspect of photoelectrochemical polymerization is that the oxidation step is guided by the difference between the potential of the valence band edge of the inorganic species (e.g., metal oxide) and the oxidation potential of the monomer. Comparing photoelectrochemically produced CPs with those prepared either chemically or electrochemically, the former is independent of the nature of the electrolyte in terms of both the generation and the electrical properties of the resulting CPs. Furthermore, photoelectrochemical polymerization allows for the deposition of CPs into micro-templates [30]. However, not all CPs can be produced by photoelectrochemical polymerization.

Overall, although chemical oxidative polymerization can produce CPs with controlled sizes and shapes, the electrochemical route provides for large-area synthesis, relatively short processing times, and good electrical, mechanical, and optical properties. Photopolymerization remains a valuable method that needs further exploration.

\subsection{Methods for Fabricating Conducting Polymer Nanomaterials}

Prior to discussing recent progress in the development of CP-based nanomaterials in detail, it is worth briefly categorizing and summarizing the template-based synthesis procedures employed to obtain various nanostructures. Generally, CPs with different nanostructures can be prepared by a number of methods, including microemulsion polymerization, template filling, and lithographic techniques (Figure 4). To the best of our knowledge, however, there are no distinct definitions of the methods, e.g., the difference between hard and soft templates is sometimes ambiguous. It should be noted that traditional classification is still not unified. For instance, some researchers consider the terms "template-free" and "self-assembly" as other names for "soft template" [1,2], whereas other studies arrange them into separate groups [3]. Therefore, we suggest a new standard for the classification, namely, the solid template approach, the molecular template approach, and the template-free approach (Table 2), which we defined in a previous study [4]. This classification is based on two aspects: the preparation step and the ability of the technique to achieve shape modification and stability. Each approach has its own merits and demerits. First, the solid template needs to be prepared before the synthesis of CPs (as-processed), whereas this is not necessary with molecular templating. Second, in solid templates, the shape of the CPs is mainly determined by the template, whereas for molecular templates, the morphology of the CPs can be varied by changing key synthetic conditions. Finally, solid template techniques are more stable than molecular templating for various conditions of temperature, $\mathrm{pH}$, additives, etc. These various approaches are discussed in the following subsections. 


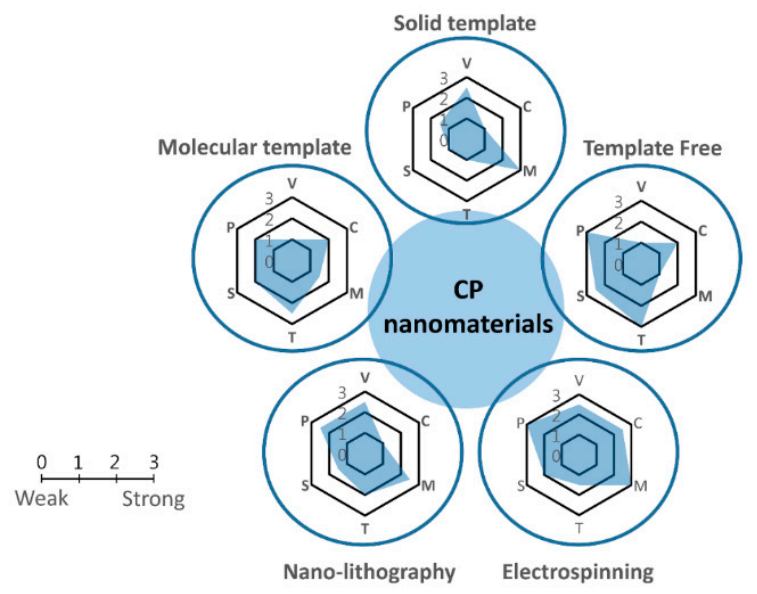

Figure 4. Schematic of the synthesis methods for $\mathrm{CP}$ nanomaterials. Each mechanism has been evaluated in term of variables $(\mathrm{V})$, in which a low value means there are many key variables in the synthesis process; cost aspect (C), in which a low value corresponds to high cost; morphology control $(\mathrm{M})$; time consumption $(\mathrm{T})$; scalability $(\mathrm{S})$; and purity $(\mathrm{P})$ of the products.

Table 2. Synthesis methods of CP nanomaterials.

\begin{tabular}{cll}
\hline Synthesis methods & \multicolumn{1}{c}{ Advantages } & \multicolumn{1}{c}{ Disadvantages } \\
\hline Solid template & $\begin{array}{l}\text { Applicable to almost all CPs. Possible to } \\
\text { precisely control the size and morphology. }\end{array}$ & $\begin{array}{l}\text { A post-synthesis process is required to remove } \\
\text { the template. Nanostructure quantity is } \\
\text { confined by the size of the template membrane. }\end{array}$ \\
\hline Molecular template & $\begin{array}{l}\text { Relatively simple, and thus scale-up is } \\
\text { possible under optimized conditions. }\end{array}$ & $\begin{array}{l}\text { Hard to provide good uniformity of size } \\
\text { and morphology. }\end{array}$ \\
\hline Template-free & Simple process without templates. & Limited to certain precursors. \\
\hline Electrospinning & Simple to produce continuous CP nanofibers. & $\begin{array}{l}\text { Only soluble and thermoplastic polymers } \\
\text { are applicable. }\end{array}$ \\
\hline Nanoimprinting & High throughput and high resolution. & An expensive micro-mold is required. \\
\hline
\end{tabular}

\subsubsection{Solid Template Approach}

The solid template method is a feasible, powerful, and controllable tool for preparing nanostructures of inorganic semiconductors, metals, and polymers. In this method, a template membrane is usually required to grow nanostructures inside pores or channels of the membrane, providing for complete control of the size and shape of the nanostructures. The solid template method is attractive as it can be used either chemically or electrochemically. For chemical template synthesis, the membrane can simply be immersed in a solution of the desired monomer, oxidant, and dopant; monomer polymerization then occurs within the pores of the membrane, which act as a template. Electrochemical template synthesis can be also accomplished by employing a metal film as an electrode at the bottom of the membrane; polymerization is subsequently carried out within the pores at an appropriate applied potential. However, because of limitations in the size and pore density of the solid template, large-scale production by the electrochemical template method is impossible. Although chemical polymerization can be controlled by adjusting the polymerization time (e.g., short time for thin-walled tubes and longer times for thick-walled tubes or fibers) and the kind and concentration of oxidizing agent, electrochemical template synthesis is more controllable via changing the applied potential or current density, as well as the deposition time and interval. The main disadvantage of the solid template method is that the template needs to be removed by post-processing, which often destroys or disorders the formed nanostructures or degrades the major properties of the CP. Polycarbonate membranes prepared by a "track-etching" method and porous alumina membranes produced by an electrochemical approach have been widely used as commercial templates. 


\subsubsection{Molecular Template Approach}

Although the solid template method gives precise control over the shape and size of CPs, it has significant drawbacks such as (1) small quantity production, (2) expensive templates; and (3) the need to use of harsh chemicals (e.g., strong acids and bases) in order to remove the template. As a result, researchers have developed molecular templates as an alternative to the solid template method. The main advantage of this approach is that it is relatively simple, inexpensive, and versatile for fabricating nanostructures. Importantly, the molecular template approach has strong potential for producing large quantities of CP nanomaterials. Many molecular templates have employed surfactants, surface micelles, liquid crystalline phases, and structure-directing molecules, which are commonly made via self-assembly mechanisms using hydrogen bonding, van der Waals forces, $\pi-\pi$ stacking, electrostatic interactions, etc. The size and morphology of the final products are predominantly determined by the pre-assembled molecular templates. Therefore, it is crucial to maintain the microstructure of the molecular template during polymerization in order to obtain the desired product. Among the various molecular template routes, the surfactant-assisted approach is widely applied because surfactant meso-phases are versatile molecular templates that are arranged in regular structures through self-assembly. Cationic cetyltrimethylammonium bromide (CTAB) [31-33], anionic sodium 4-[4-(dimethylamino) phenyldiazenyl]benzenesulfonate (MO) [34,35], sodium dodecylsulfonic acid (SDS) [36-38], sodium dodecylbenzenesulfonate (SDBS) [23] and non-ionic isooctylphenyl ether (Triton $\left.{ }^{\mathrm{TM}} \mathrm{X}-100\right)[39,40]$ are conventional surfactants that have been widely used to prepare $\mathrm{CP}$ nanomaterials with different morphologies in several polymerization systems.

In general, the disadvantage of such a method is the poor control of the size, morphology, and orientation of the $\mathrm{CP}$ nanostructures [6], which has prevented wide utilization of molecular template synthesis. In order to resolve the limitations of this method (the equilibrium shape and size of surfactant aggregates), numerous factors must be considered, such as the geometry of the template molecules (for example, in the case of micelles, the length of the surfactant tail in the hydrophobic core and the volume and effective area of each surfactant head group) [1].

\subsubsection{Template-Free Approach}

In order to circumvent the drawbacks of the template approach, the development of synthesis methods without using templates has been studied. It should be noted that the use of a template increases the cost of the synthesis and may also either modify or damage the properties of the synthesized nanostructures. Hence, a template-free method is highly attractive because a template is not required for either the synthesis or the stabilization of the nanostructures.

One of the frequently cited methods is in situ polymerization using protonic acids (e.g., $\beta$-naphthalenesulfonic acid) as dopants [41]. The main feature of this method is that the micelle-like structures formed by the monomer and dopant act as "molecular templates" during polymerization. The template-free approach has great potential for preparing unique micro- or nanostructures that cannot be fabricated by the solid template approach due to the limitations imposed by the pore structure of the template used. Indeed, the template-free route is attractive owing to its low cost, simplicity, and flexibility for thin-film device fabrication. Nevertheless, the mechanisms of self-assembly are quite complicated and not clearly understood. The template-free method limits precise control of the morphology and properties, a drawback that is similar to that of the molecular template approach [3].

\subsubsection{Other Methods}

Some publications have reported other methods for producing CP nanostructures. For example, soft lithography is a low-cost, high-resolution, and high-throughput approach to fabricating nanoscale patterns using a micro-mold, sometimes with the assistance of solvent vapors or temperature control [42]. In addition, the directed electrochemical nanowire assembly technique has been used to grow CP nanowires [43]. Among the physical methods used to prepare CP nanomaterials without 
templates, electrospinning is one of the most popular methods because it is easy and effective for generating long $\mathrm{CP}$ nanofibers using strong electrostatic forces. As compared to other synthesis routes, the electrospinning process seems to be the only method that can produce continuous long nanofibers. However, to achieve good fiber formation, some non-conducting polymers (e.g., polyethylene oxide (PEO)) are usually added for the purpose of tailoring the viscosity of the mixture [44]. Furthermore, the nanofibers may exhibit a substantial concentration of defects and a large size distribution, which limit the application of electrospinning.

\subsection{Synthesis Methods for CP Nanohybrids}

Based on the mechanism and procedure for the fabrication of $\mathrm{CP}$ nanohybrids, the methodologies may be classified into three main categories: (i) ex situ (sequestered) synthesis, (ii) in situ (sequential) synthesis; and (iii) one-pot (concurrent) synthesis [5], as represented in Table 3 and Figure 5. The main characteristic of all the methods in the first category is that the CPs and inorganic species are synthesized separately, and the hybridization is achieved during a subsequent step by simple or more complex blending of two or more components in which interfacial tension between the different components determines the major properties of the resulting nanohybrids. These procedures are simple and usually highly suitable for solution-based processing, which is a milestone for enabling mass production and processing via roll-to-roll printing. Another benefit of these methods is the well-established synthesis procedures because each component is manufactured separately using a known process. As for the hybridization process, there are various valuable strategies available, ranging from very simple methods such as mechanical mixing of the two components, to more sophisticated methods such as ligand exchange or layer-by-layer fabrication procedures [45-47]. Finally, physical infiltration of CPs into inorganic nanostructures can also be achieved, resulting in highly ordered nanoarchitectures $[48,49]$. However, this process is not straightforward because the polymeric guest materials may be prevented from infiltrating the pores of the nanostructured host due to high interfacial tension as a result of physical limitations such as the hydrodynamic radius of the polymer, leading to incomplete pore filling; pore-filling ratios as low as $0.5 \%$ have been obtained. Finally, differences in the hydrophobic/hydrophilic nature of the two components can further limit the application of such procedures.

Table 3. Preparation methods for synthesizing CP nanohybrids.

\begin{tabular}{clll}
\hline Main Group & \multicolumn{1}{c}{ Advantage } & \multicolumn{1}{c}{ Disadvantage } & Example \\
\hline Ex situ synthesis & Simple Solution-processable & $\begin{array}{l}\text { Limited applications Poor } \\
\text { control of the contact } \\
\text { between each component }\end{array}$ & $\begin{array}{l}\text { Mechanical mixing } \\
\text { Layer-by-layer } \\
\text { deposition }\end{array}$ \\
\hline In situ synthesis & $\begin{array}{l}\text { Variable methods based on } \\
\text { chemical or electrochemical } \\
\text { route. Facile control of } \\
\text { many variables }\end{array}$ & $\begin{array}{l}\text { Higher complexity as many } \\
\text { parameters need to } \\
\text { be considered }\end{array}$ & $\begin{array}{l}\text { In situ polymerization. } \\
\text { Electrodeposition. } \\
\text { [n situ reduction }\end{array}$ \\
\hline One-pot synthesis & Simple Short processing time & $\begin{array}{l}\text { Limited control over } \\
\text { structure and morphology } \\
\text { of the products }\end{array}$ & $\begin{array}{l}\text { Redox reaction } \\
\text { Co-deposition }\end{array}$ \\
\hline
\end{tabular}

In the second category of methods (in situ synthesis), at least one component of the nanohybrid is generated in the presence of its counterpart. These techniques can be further classified on the basis of the component formed in situ. It is apparent that nanohybrids obtained by in situ methods may have several advantages over their $e x$ situ-prepared counterparts because the organic/inorganic interface can be better controlled at the molecular level. Specifically, first, in the case of the electrochemical in situ route, heterogeneous components can be incorporated into CPs grown in the form of a film on the electrode surface [56]. One benefit of such an approach is that the structure and properties of the hybridized material can be controlled by changing the critical variables such as deposition time and 
current density. Although a higher current density leads to faster growth, it is not easy to control, and the polymer may be insufficiently compact. For chemical in situ syntheses, formation of the nanohybrid is rather straightforward. Most methods focus on strategies where the CPs are formed in the presence of the inorganic species; however, the opposite is also possible, namely, the inorganic component is synthesized in situ within the CP. Wet-chemical co-precipitation is an approach for synthesis of CPs with an oxidant such as $\mathrm{KMnO}_{4}$ or $\mathrm{FeCl}_{3}$, resulting in hybridized structures [57].

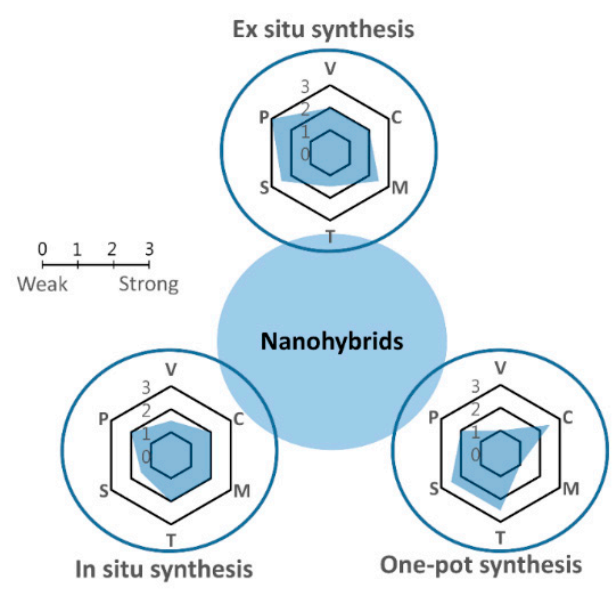

Figure 5. Schematic of nanohybrid synthesis methods. Each mechanism has been evaluated in terms of variables $(\mathrm{V})$, in which a low value means there are many key variables in the synthesis process; cost $(\mathrm{C})$, in which a low value corresponds to high cost; morphology control (M); time required (T); scalability (S); and purity (P) of products.

Lastly, the third category, namely one-pot syntheses is probably the simplest (but least controllable) method. These "one-pot" synthesis methods are fundamentally based on in situ reactions that form organic/inorganic phases simultaneously in a single stage. Both chemical and electrochemical processes can be applied to this group, but co-electrodeposition is more attractive [55]. The general disadvantage of these methods is the poor control of the size and morphology of the resultant hybridized materials.

\section{Progress in CP Nanomaterial Synthesis}

\subsection{Recent Advances in the Synthesis of CP Nanomaterials}

The most significant trials in liquid-phase polymerization have relied on the utilization of templates for controlling the morphology of CPs on a nanometer scale, where solid templates are an excellent candidate for many applications. For example, Huang's group proposed a strategy using anion spherical polyelectrolyte brushes (ASPB) with silica cores as templates and dopants for the synthesis of conductive copolymer nanocomposites [58]. The highlights of this route can be summarized as follows: (i) the symmetrical spherical structure of the ASPB can guarantee a spherical morphology with enhanced conductivity, and (ii) charged polymer chains can still be included on the periphery of the nanocomposites via control of the length of the brushes and the thickness of the CP shells to improve the stability of the suspension of the nanoparticles. The poly(styrene sulfonate) (PSS) chains on the silica core surfaces not only facilitate uniform deposition of the conducting copolymer poly(aniline-co-pyrrole) through electrostatic interaction, they also serve as anionic dopants for the copolymer. Thus, a high concentration of monomers is mainly distributed close to the cores of the ASPB. Similarly, Zhang et al. [59] used $\mathrm{TiO}_{2}$ nanotube-PSS as a template and dopant for the synthesis of PPy. The advantages of using $\mathrm{TiO}_{2}$-PSS are similar to those of using ASPB because it too exhibits the ability to capture and control the ions within the layer of PSS chains via electrostatic interaction. Then, pyrrole monomers are oxidized by ferric ions in the shell of the PSS to generate PPy. 
Block copolymers can also be used as templates, where CPs are generally synthesized in a microphase-separated domain. For example, Komiyama et al. [60] reported electropolymerization of pyrrole and bithiophene (BiTh) using PEO-filled cylindrical domains of a microphase-separated $\mathrm{PEO}_{m}-b-\mathrm{PMA}(\mathrm{Az})_{n}$ as a template, where the $\operatorname{PMA}(\mathrm{Az})$ indicates polymethacrylate with azobenzene-mesogen in side chain. The results were very impressive: while one-pot polymerization gave lateral-composition-modulated copolymer structures, stepwise polymerization created PPy-PEDOT or PEDOT-PPy nanowire heterojunctions (Figure 6).
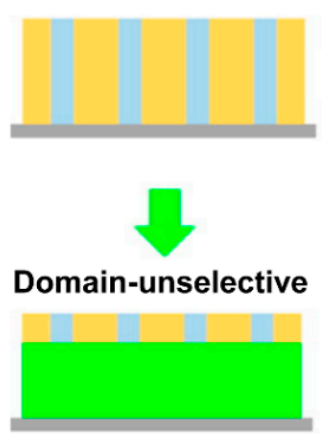

Film
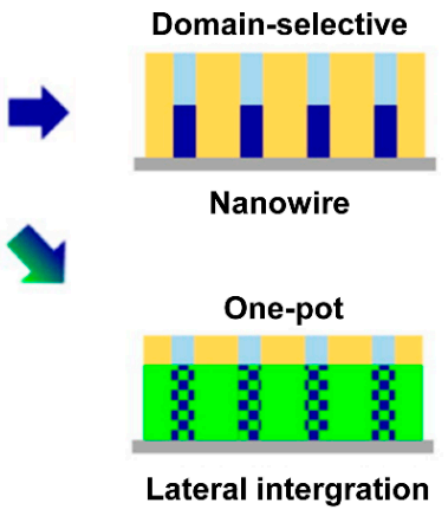
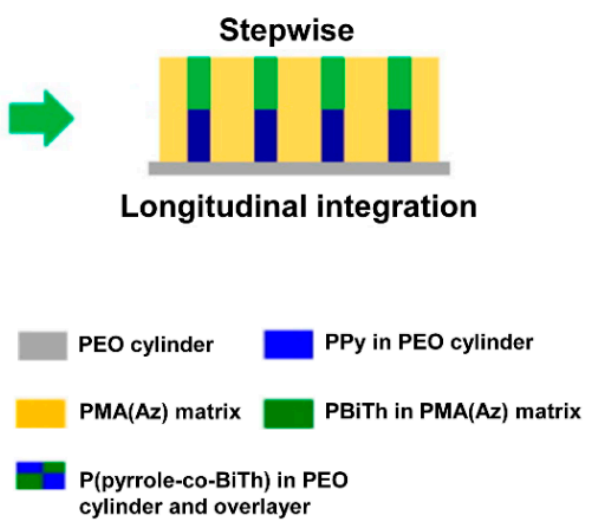

Figure 6. Comparison of stepwise (above) and one-pot (below) electropolymerization using $\mathrm{PEO}_{m}-b$-PMA(Az) $)_{n}$ (polymethacrylate with azobenzene-mesogen in side chain )block copolymer as a template. Reprinted with permission from [60]. Copyright 2015, American Chemical Society.

As a possible milestone for industrial fabrication of colloidal crystal templates, Choi et al. [61] demonstrated an efficient method to fabricate large-area two-dimensional (2D) colloidal crystals as a template for nanopatterning of CPs; this method involves the electrophoretic deposition of negatively charged polystyrene colloidal particles and the assembly of the colloidal particles to 2D colloidal crystals at the air-water interface. Similarly, other solid template methods have been developed, such as nanosphere lithography-mediated electrodeposition [62,63], in which Langmuir-Blodgett deposition and drop casting were used to fabricate nanosphere templates.

Although the nanostructural fabrication of CPs has been achieved with nanoporous solid templates via electropolymerization, this process is still challenging. In particular, templates with high-aspect-ratio nanopores suffer from poor monomer diffusion in liquid-phase polymerization. A solution for this problem might be the use of supercritical fluids such as supercritical trifluoromethane $\left(\mathrm{scCHF}_{3}\right)$, which has a relatively high solubility and dielectric constant without the need for additives (e.g., polar solvents) [64,65]. Supercritical fluids are characterized by lower viscosities and large diffusivities as compared to conventional liquids because the physicochemical properties of supercritical fluids are intermediate between those of liquids and gases.

Molecular templating has also continued to play a key role in $\mathrm{CP}$ synthesis. Note that molecular templating is not only used to control the morphology of the resultant nanoparticles [66], it also affects the doping state of the CPs, which determines the electrical properties [67]. A recent notable example of such a formation mechanism is outlined in Figure 7. PPy hollow nanoparticles with different diameters were prepared by surfactant templating and their electrical properties depended on the size. Devaki et al. [68,69] explored liquid crystalline templates with an inexpensive and abundantly available industrial by-product, the main constituent of cashew nut shell extract, namely, cardanol(3-pentadecylphenol). This approach might be a good alternative to traditional petroleum-based surfactants, which have become expensive owing to increased demand and depletion of resources. Acid derivatives of cardanol, including 3-pentadecyl phenol-4-sulfonic acid and 3-pentadecylphenyl phosphoric acid, have a unique amphiphilic design, with the acid group as a hydrophilic head group and a long alkyl chain as a hydrophobic tail. Importantly, the monomer 
3,4-ethylenedioxythiophene (EDOT) formed liquid crystalline templates of various shapes with the acid derivative of cardanol, such as discs, gyroids, columns, and lamella.
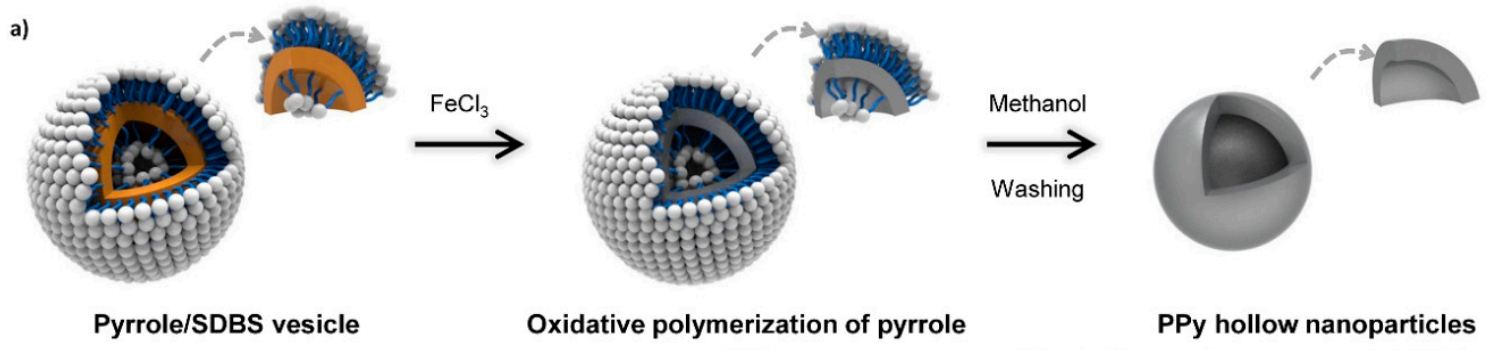

Oxidative polymerization of pyrrole

b)
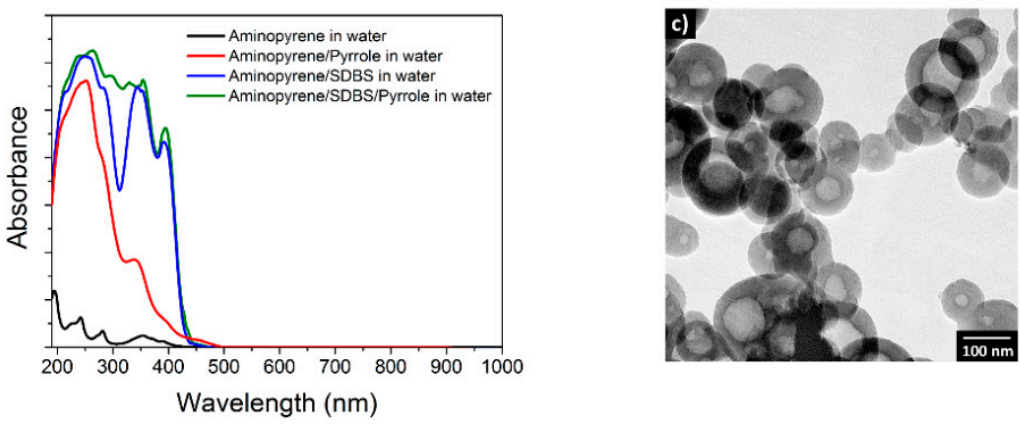

PPy hollow nanoparticles

Figure 7. Preparation of PPy hollow nanoparticles. (a) Schematic of the formation mechanism, (b) UV-vis absorption spectra of aminopyrene in different solvents; (c,d) Transmission electron microscopy (TEM) images of the hollow PPy nanoparticles with diameters of 100 and $200 \mathrm{~nm}$, respectively. Reprinted with permission from [67]. Copyright 2015, Nature Publishing Group.

Much effort has been invested in finding the best composition for use as a molecular template. For instance, Dutt et al. [36] fabricated swollen liquid crystalline templates with a quaternary mixture containing brine, SDS as a surfactant, 1-pentanol as a co-surfactant, and cyclohexane oil. In addition, insoluble complex templates with lamellar mesostructures were formed with a noble metal compound and a cationic surfactant such as CTAB [70]. Other surfactants that have been investigated include indigo carmine [71] and Pluronic ${ }^{\circledR}$ F127 [72].

By combining templates, including solid and molecular templates, many interesting results have been reported. Sharma and co-workers [73] employed monodispersed poly(methyl methacrylate) (PMMA) colloids $\sim 430 \mathrm{~nm}$ in diameter as three-dimensional (3D) colloidal crystal templates and SDBS as a surfactant for fabricating 3D macroporous PPy inverse opals. There are three main advantages to this method: (i) although PMMA colloids are solid templates and require chemical treatment to remove them, they can be easily dissolved by common solvents, (ii) the inverse opal PPy presented a higher surface area $\left(19.2 \mathrm{~m}^{2} \cdot \mathrm{g}^{-1}\right)$ as compared to conventional non-porous PPy films $\left(4.8 \mathrm{~m}^{2} \cdot \mathrm{g}^{-1}\right)$; and (iii) SDBS not only acts as a surfactant but also a dopant for PPy to trap cations present in the surrounding solution. Other new developments for combining templating methods have also been reported. Rivero et al. [74] designed a new approach using mesostructured $\mathrm{SiO}_{2}$ as a solid template to synthesize self-doping copolymer poly(aniline-co-aminobenzoic acid) in the presence of CTAB. When CTAB was added to the synthesis medium, the silica template showed well-ordered growth with parallel channels approximately $2-3 \mathrm{~nm}$ in width. On the other hand, in the CTAB-free precursor solution, a microporous silica deposit was obtained. It should be noted that the redox current response of the as-prepared film appeared only after the surfactant molecules were removed [75]. Moreover, the effect of the time when the anionic surfactant SDS was added during the template polymerization of the CPs was also investigated [76].

Using a method based on template-free electrochemical polymerization, Liao et al. [77] successfully fabricated PPy nanostructures of several different morphologies on a prenucleated PPy thin film and 
examined their growth mechanism using 3D AFM imaging and field-emission scanning electron microscopy (FE-SEM). Interestingly, $\beta$-naphthalenesulfonic acid used as a dopant led to differences in the self-assembly behavior of further growing PPy chains at different redox states. These differences determined the final morphology of the PPy nanostructure.

Various impressive approaches have also been developed, such as direct growth by chemical micropatterning [78], bipolar electrochemistry [79,80], enzymatic polymerization using sodium bis(2-ethylhexyl) sulfosuccinate (AOT) as a template [81], and edge nanoimprint lithography [82]. However, due to their complexity, such methods are not popular for the synthesis of $\mathrm{CP}$ nanomaterials for applications, and they will require significant time for improvement. Table 4 lists representative examples of synthesis methods for CP nanomaterials developed over the last three years.

Table 4. Representative examples of fabrication methods for CP nanomaterials developed over the last three years.

\begin{tabular}{|c|c|c|c|}
\hline $\mathrm{CP}$ & Polymerization method & Details & Refs. \\
\hline \multirow{7}{*}{ PANI } & $\begin{array}{l}\text { Amyloid nanofiber template } \\
\text { polymerization }\end{array}$ & $\begin{array}{l}\text { Amyloid nanofibers were successfully used as } \\
\text { templates for the formation of conductive } \\
\text { core-shell nanowires }\end{array}$ & {$[83]$} \\
\hline & Planar DNA template & $\begin{array}{l}\text { Production of CPs with controlled shapes on } \\
2 \mathrm{D} \text { polyelectrolyte templates was investigated } \\
\text { for the first time }\end{array}$ & {$[84]$} \\
\hline & $\begin{array}{l}\text { Electrospinning using poly(amic acid) } \\
\text { fiber as a template }\end{array}$ & $\begin{array}{l}\text { Hollow nanofibers with controllable wall } \\
\text { thicknesses were successfully obtained }\end{array}$ & [85] \\
\hline & Dedoped chemical polymerization & $\begin{array}{l}\text { Water-dispersed CP nanofibers with high } \\
\text { capacitance were achieved by double doping }\end{array}$ & [12] \\
\hline & Biphase interfacial polymerization & $\begin{array}{l}\text { The mechanism for self-assembly in crystalline } \\
\text { 1D nanostructures was investigated }\end{array}$ & [86] \\
\hline & Surface-initiated polymerization & $\begin{array}{l}\text { A new approach for multimodal core-shell } \\
\text { nanoparticles with a stable doping state was } \\
\text { reported }\end{array}$ & {$[87]$} \\
\hline & Interfacial polymerization & $\begin{array}{l}\text { A novel hollow PANI nanocapsule with holes } \\
\text { in the wall was synthesized }\end{array}$ & {$[88]$} \\
\hline \multirow{2}{*}{ PPy } & $\begin{array}{l}\text { Time-dependent template-assisted } \\
\text { polymerization }\end{array}$ & $\begin{array}{l}\text { A new synthesis approach for the precise } \\
\text { control of wall morphologies of colloidal } \\
\text { microparticles was studied }\end{array}$ & {$[89]$} \\
\hline & Modified pulse potentiostatic method & $\begin{array}{l}\text { A good method to control the shape of micelles } \\
\text { at the substrate/electrolyte interface and } \\
\text { control the morphology of CPs was proposed }\end{array}$ & {$[90]$} \\
\hline \multirow{3}{*}{ PEDOT } & Galvanostatic electrodeposition & $\begin{array}{l}\text { Good result combining a carboxylated } \\
\text { polystyrene template made by nanosphere } \\
\text { lithography with SDS as a molecular template } \\
\text { was achieved }\end{array}$ & {$[91]$} \\
\hline & Non-spontaneous emulsification & $\begin{array}{l}\text { A novel method using colloidal chemistry to } \\
\text { fabricate multifunctional CPs was developed }\end{array}$ & [92] \\
\hline & $\begin{array}{l}\text { Electron pulse-enabled in situ } \\
\text { polymerization }\end{array}$ & $\begin{array}{l}\text { The mechanism of CP growth was investigated } \\
\text { experimentally and via modeling }\end{array}$ & {$[93]$} \\
\hline
\end{tabular}

In addition to the development of templating techniques to synthesize CP nanomaterials, the investigation of various crucial processing factors has been undertaken. For the chemical route, these include oxidant/monomer ratio and washing post-treatment [9], the chemical effects of the solvent (solvent-free versus solvent-limited syntheses) [10], effects of the dopant (D-tartaric acid [11], aromatic and amphiphilic sulfonate [17]), and the polymerization kinetics [94,95]. For the electrochemical approach, investigations of the deposition potential and temperature [96] and chloroform as the environment [97] have been undertaken. Finally, a new anionic dopant, sulfanilic acid azochromotrop [18], was investigated for a combination of chemical and electrochemical polymerization $[13,14]$. Based on the electrochemical route, the electrophoretic force was successfully 
exploited for the deposition and assembly of CP nanomaterials. As compared to other approaches, electrophoresis offers advantages such as additional controllable synthetic parameters, high deposition rate, and large-area processing, factors that are essential for industrial manufacturing. Although good results have been achieved for doped CPs patterned onto microscale templates by electrophoresis, the dimensions of the assembled CPs were limited to the micron scale. In order to solve this problem, Shen et al. [98] made PANI directly assembled onto multiscale sub-micron templates using a dielectrophoretic technique. In electrophoretic assembly, by applying a uniform electric field, charged "particles" are deposited onto electrodes in a solution, whereas with dielectrophoretic assembly, the "particles" are subjected to a non-uniform electric field and thus need not be charged. The dielectrophoresis approach has advantages over electrophoresis, such as avoiding oxidation of the template surface, meaning that the template can be reused and the materials can be assembled without charging. Consequently, PANI was successfully deposited uniformly onto 100-nm-wide electrodes with multiple length scales.

For non-liquid phase polymerization, the two main routes are solid phase and vapor phase (Table 5). Solid-phase polymerization is rarely used for CP synthesis, although it is very simple. Bhandari et al. [99] presented the first study of PANI nanowires prepared using a mechanochemical route; however, to date, the advantages of such a method are not clear. Meanwhile, the two methods for synthesizing CPs in a vapor phase are quite efficient, namely vapor-phase polymerization (VPP, often called vapor deposition polymerization, VDP) and chemical vapor deposition (CVD). The distinction between these methods is in how the initiator is applied during polymerization. The initiator and monomer must be in a vapor phase in the CVD process, whereas only the monomer needs to be in the vapor phase for VPP. The morphology of CPs using the VPP method is highly affected by the synthesis conditions, as well as by the substrate curvature [100]. As compared to liquid-phase polymerization, CVD and VPP can produce thinner films with better reproducibility and higher crystallinity and conductivity. To date, vapor-phase synthesis has provided unique possibilities in terms of tuning the synthesis process of CPs; even multi-dimensional CP nanostructures can be fabricated via this route [101]. The latest work reported that co-vapors can be introduced into the VPP process to modulate the morphology and properties of the resulting CP product (Figure 8) [82]. It was found that co-vapors such as alcohols and water can affect (i) the vaporization of the monomer, (ii) the orientation of forming polymer chains; (iii) the rate and efficiency of oxidative polymerization; (iv) the swelling of the substrate; and (v) the diffusion of the monomer into the substrate, all of which lead to significant changes in the characteristics of the resultant $C P$.

Table 5. Representative reports for the solid/vapor-phase polymerization of CP nanomaterials.

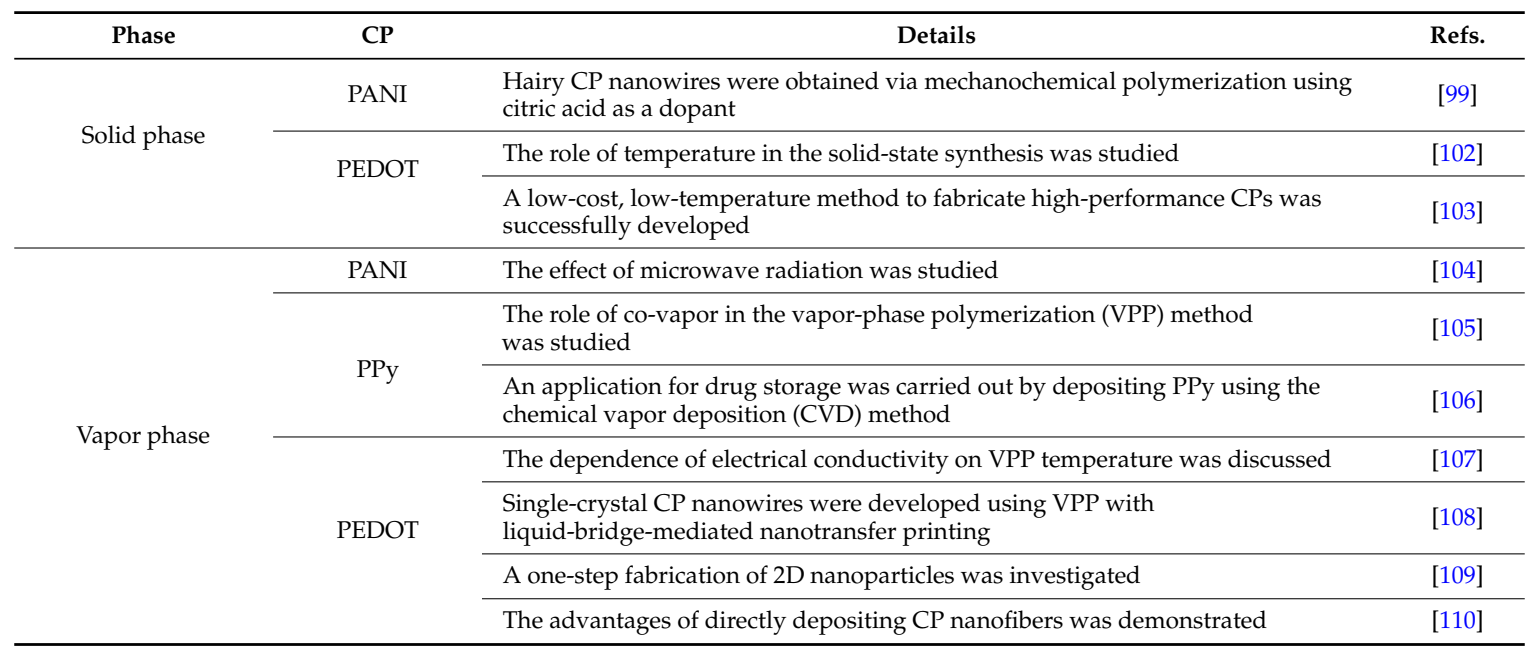


a)

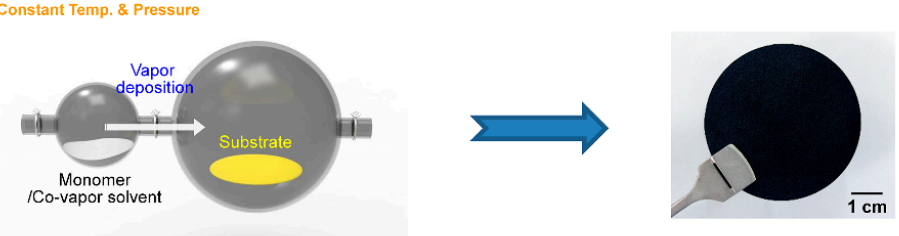

Large-area, flexible conductive papers
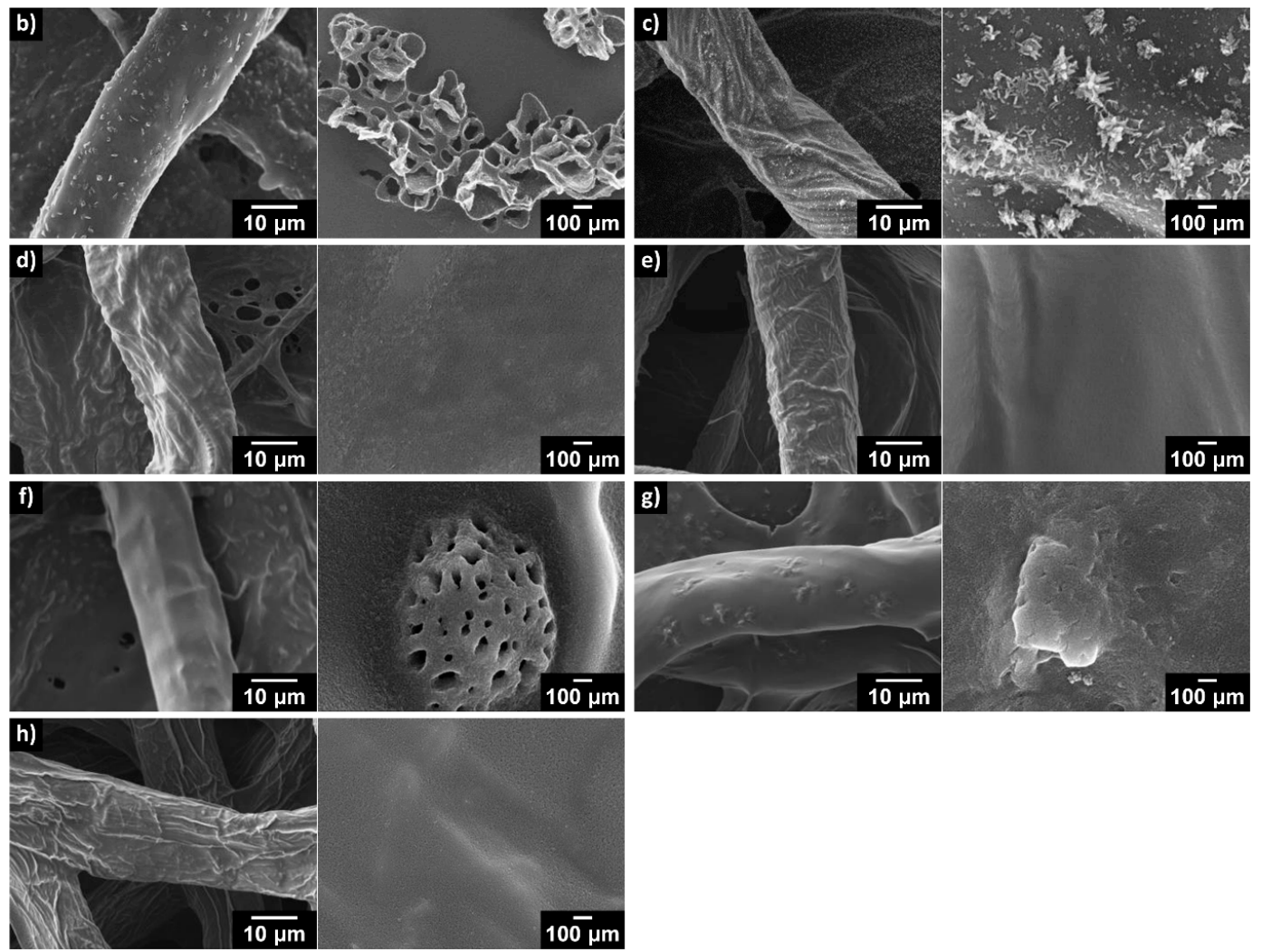

Figure 8. (a) Vapor-phase polymerization (VPP) of pyrrole with co-vapors on a cellulose substrate and a typical photograph of as-prepared paper; $(\mathbf{b}-\mathbf{h})$ Scanning electron microscopy (SEM) images of papers prepared with co-vapors: (b) methanol, (c) ethanol; (d) water; (e) hexane; (f) toluene; (g) benzene; and (h) no vapors. (left: low magnification, right: high magnification). Reprinted with permission from [105]. Copyright 2015, Nature Publishing Group.

\subsection{Novel Trends for Synthesis of CP Nanohybrids}

Recently, nanohybrids have fascinated many researchers because of their usefulness in many applications. The fabrication of these hybrids can be commonly achieved via the combination of CPs and inorganic species in the nanometer regime, as discussed above. A notable example is manganese oxide $\left(\mathrm{MnO}_{x}\right) / \mathrm{CP}$ nanohybrids $[51,67,111,112]$. Because $\mathrm{MnO}_{x}$ can act as a reactive template in an acidic medium for the chemical polymerization of $\mathrm{CP}$, direct $\mathrm{CP}$ nanocoating has been made on the surface of $\mathrm{MnO}_{x}$. The resulting nanohybrids with an optimized ratio of $\mathrm{MnO}_{x} / \mathrm{CP}$ showed the following merits: (i) the coated $\mathrm{CP}$ provided conductive pathways for better utilization of $\mathrm{MnO}_{x}$, and (ii) both $\mathrm{MnO}_{x}$ and $\mathrm{CP}$ exhibited synergistic electrochemical properties. It has been noted that the properties of hybrid nanomaterials may vary significantly depending on the preparation methods even for the same materials. Characteristics of the preparation methods can be recognized by comparing the synthesis examples of $\mathrm{MnO}_{2} / \mathrm{PANI}$ using adsorption templates [113] and reactive templates [114,115]. Interestingly, in electrochemical capacitor applications, the results using the adsorption template method showed higher specific capacitances than their counterparts using the reactive template 
method. As a partial summary, Table 6 shows several representative examples for nanohybrid synthesis using CPs and metal- or metal oxide-based species.

Table 6. Representative examples of the incorporation of inorganic species into CPs.

\begin{tabular}{|c|c|c|c|c|}
\hline $\mathrm{CP}$ & Inorganic species & Preparation method & Details & Refs. \\
\hline \multirow{8}{*}{ PANI } & $\mathrm{Au}$ & Interfacial polymerization & $\begin{array}{l}\text { The formation mechanism of } \\
\text { Au-PANI was presented }\end{array}$ & [116] \\
\hline & $\mathrm{Cu}$ & Concurrent synthesis & $\begin{array}{l}\text { The structure of a } \mathrm{Cu} / \mathrm{PANI} \text { hybrid } \\
\text { was studied }\end{array}$ & [117] \\
\hline & $\mathrm{Pd}$ & Layer-by-layer technique & $\begin{array}{l}\text { A Pd/PANI/Pd sandwich-structure } \\
\text { nanotube array was first reported }\end{array}$ & [46] \\
\hline & $\mathrm{TiO}_{2}$ & $\begin{array}{l}\text { Combination of hydrothermal and } \\
\text { electropolymerization }\end{array}$ & $\begin{array}{l}\text { A multicolor electrochromic film was } \\
\text { fabricated based on hybrid core-shell } \\
\text { nanorod arrays }\end{array}$ & [118] \\
\hline & $\mathrm{CdO}$ & Chemical oxidative polymerization & $\begin{array}{l}\text { Aqueous diethylene glycol solution } \\
\text { medium was used for the first time }\end{array}$ & [119] \\
\hline & $\mathrm{MoS}_{2}$ & $\begin{array}{l}\text { Vertically aligned chemical } \\
\text { polymerization }\end{array}$ & $\begin{array}{l}\text { A good example of hybrid 3D tubular } \\
\text { structures was discussed }\end{array}$ & [120] \\
\hline & $\mathrm{Se}_{0.5} \mathrm{Te}_{0.5}$ & Lyotropic liquid crystalline template & $\begin{array}{l}\text { A mesoporous dual-layer film was } \\
\text { synthesized using Brij56 surfactant }\end{array}$ & [121] \\
\hline & $\mathrm{MnFe}_{2} \mathrm{O}_{4}$ & Incorporative polymerization & $\begin{array}{l}\text { Dual nature of hybrid (cathode } \\
\text { catalyst and anode modifier) was first } \\
\text { demonstrated }\end{array}$ & [122] \\
\hline \multirow{10}{*}{ PPy } & \multirow[t]{2}{*}{$\mathrm{Ag}$} & $\begin{array}{l}\text { Incipient network conformal growth } \\
\text { technology }\end{array}$ & $\begin{array}{l}\text { A new porous material, namely, an } \\
\text { "aero-sponge," was proposed }\end{array}$ & [123] \\
\hline & & Cathodic co-deposition & $\begin{array}{l}\text { Highly stable sensing activity of the } \\
\text { hybrid was studied }\end{array}$ & [124] \\
\hline & $\mathrm{MnO}_{2}$ & Electropolymerization & Effect of deposition time was reported & [51] \\
\hline & $\mathrm{ZnO}$ & $\begin{array}{l}\text { Ultrasound-assisted chemical } \\
\text { polymerization }\end{array}$ & $\begin{array}{l}\text { Well-controlled granular and layered } \\
\text { nanocomposite was formed }\end{array}$ & [125] \\
\hline & $\mathrm{CuO}$ & Wire template technique & $\begin{array}{l}\text { The previous method was extended to } \\
\text { study polymerization time }\end{array}$ & [126] \\
\hline & $\mathrm{CoO}$ & $\begin{array}{l}\text { Modified hydrothermal and } \\
\text { post-annealing process }\end{array}$ & $\begin{array}{l}\text { 3D growth of well-aligned nanowire } \\
\text { array was developed }\end{array}$ & [127] \\
\hline & $\mathrm{MoS}_{2}$ & In situ intercalative polymerization & $\begin{array}{l}\text { A facile strategy for intercalation of } \\
\text { PPy into } \mathrm{MoS}_{2} \text { nanosheets was } \\
\text { proposed }\end{array}$ & [128] \\
\hline & $\mathrm{TiO}_{2}$ & $\begin{array}{l}\text { Pulsed-light and pulsed-potential } \\
\text { method }\end{array}$ & $\begin{array}{l}\text { Good control of the deposition rate } \\
\text { was demonstrated }\end{array}$ & [129] \\
\hline & $\mathrm{LiV}_{3} \mathrm{O}_{8}$ & $\begin{array}{l}\text { Low-temperature in situ } \\
\text { polymerization }\end{array}$ & $\begin{array}{l}\text { A new anode material for rechargeable } \\
\text { lithium batteries was reported }\end{array}$ & [130] \\
\hline & $\mathrm{ZnCo}_{2} \mathrm{O}_{4}$ & $\begin{array}{l}\text { Reflux method and chemical } \\
\text { polymerization }\end{array}$ & $\begin{array}{l}\text { A facile method for fabricating } \\
\text { mesoporous } \mathrm{ZnCo}_{2} \mathrm{O}_{4} \text {-coated PPy was } \\
\text { developed }\end{array}$ & [131] \\
\hline PT & $\mathrm{ZnO}$ & Electropolymerization growth & $\begin{array}{l}\text { Interfacial bonding and morphology } \\
\text { control was described }\end{array}$ & [16] \\
\hline \multirow{2}{*}{ PEDOT } & $\mathrm{V}_{2} \mathrm{O}_{5}$ & $\begin{array}{l}\text { "Cocoon-to-silk" fiber reeling } \\
\text { method }\end{array}$ & $\begin{array}{l}\text { First method for fabricating layered } \\
\mathrm{V}_{2} \mathrm{O}_{5} / \text { PEDOT nanowires was } \\
\text { reported }\end{array}$ & [132] \\
\hline & Iron oxide * & $\begin{array}{l}\text { Spin-coated-assisted deposition } \\
\text { with "supporting layer technique" }\end{array}$ & $\begin{array}{l}\text { A new simple, fast, and inexpensive } \\
\text { technique for the fabrication of a } \\
\text { free-standing hybrid was reported }\end{array}$ & [133] \\
\hline $\mathrm{CP}^{* *}$ & $\mathrm{Ag}, \mathrm{Au}, \mathrm{CdSe}$ & RAFT polymerization & $\begin{array}{l}\text { Role of the direct covalent attachment } \\
\text { was emphasized }\end{array}$ & [134] \\
\hline
\end{tabular}


In general, a high-surface-area composite with high conductivity is desired to achieve superior performance for applications of CPs. Therefore, in addition to the optimization of the main properties such as electrical conductivity, proper control of the corresponding morphology (such as pore size and specific surface area) is critical. Using simple thermal treatments and chemical VPP, Yang et al. [111] successfully synthesized $\mathrm{MnO}_{2}$ nanoparticles/PEDOT porous hybrids. The highlight of this porous hybrid is an "open" porosity, resulting in excellent electrochemical activity due to the synergistic properties between the nanoparticles and CPs, even though the electrical conductivity decreased with increasing nanoparticle content.

One of the most well-known routes for in situ synthesis of CPs within a nanostructured host metal oxide is the infiltration method. The simplest approach is physical infiltration; however, such infiltration is often hindered due to the high interfacial tension between the host and the guest. In addition, the combination of the physical infiltration approach and electrochemical polymerization requires positive potentials, which can result in irreversible oxidation of the CPs. Using photoelectrochemical polymerization, Samu et al. [75] overcame this problem. As a first step, an EDOT monomer is oxidized by photogenerated holes on the surface of a metal oxide. The polymerization is initiated by sensitizer nanoparticles. Next, the electrochemical growth of PEDOT starts to take place predominantly on the surfaces of the nanoparticles. Mazzotta et al. [30] also successfully demonstrated that highly flexible CP microstructures can be achieved from a silicon template via light-activated electrochemical processes. A summary of recent photosynthesis studies for CP nanohybrids reported in the literature is given in Table 7.

Table 7. Representative examples for photosynthesis of CP nanohybrids.

\begin{tabular}{|c|c|c|c|}
\hline Material & Preparation method & Details & Refs. \\
\hline \multirow{2}{*}{ PPy/Ag } & $\begin{array}{l}\text { One-pot UV-induced } \\
\text { photopolymerization }\end{array}$ & $\begin{array}{l}\text { Effect of concentration ratio of composite in cellulose } \\
\text { fabric was studied }\end{array}$ & [135] \\
\hline & $\begin{array}{l}\text { One-step interfacial } \\
\text { photopolymerization }\end{array}$ & $\begin{array}{l}\text { Thin, flexible nanofilms were synthesized at the } \\
\text { water-air interface }\end{array}$ & [136] \\
\hline \multirow[b]{2}{*}{$\mathrm{PPy} / \mathrm{TiO}_{2}$} & Photo-assisted electrodeposition & Effect of $\mathrm{LiClO}_{4}$ in the presence of SDBS was investigated & [23] \\
\hline & $\begin{array}{l}\text { Photoelectrochemical } \\
\text { polymerization }\end{array}$ & $\begin{array}{l}\text { Properties of nanohybrid in the presence of SDS } \\
\text { was studied }\end{array}$ & [22] \\
\hline $\mathrm{PPy} / \mathrm{WO}_{3}$ & In situ photopolymerization & A room-temperature $\mathrm{H}_{2} \mathrm{~S}$ gas sensor was fabricated & [24] \\
\hline PPy/ceria & Photo-induced polymerization & $\begin{array}{l}\text { A good example of one-step photopolymerization } \\
\text { was shown }\end{array}$ & [137] \\
\hline PPy/methacrylate & $\begin{array}{l}\text { UV and visible light } \\
\text { photopolymerization }\end{array}$ & $\begin{array}{l}\text { The mechanism of photopolymerization with iodonium } \\
\text { salt was presented }\end{array}$ & [138] \\
\hline $\mathrm{PPy} / \mathrm{AgBr} / \mathrm{Ag}$ & $\begin{array}{l}\text { Microemulsion } \\
\text { photopolymerization }\end{array}$ & $\begin{array}{l}\text { Effect of different concentrations of cationic surfactant } \\
\text { CTAB was studied }\end{array}$ & [31] \\
\hline PT/epoxy & One-pot photoinduced synthesis & $\begin{array}{l}\text { A novel methodology for fabricating a network film } \\
\text { was given }\end{array}$ & [20] \\
\hline Clay/PPy/Ag & In situ photopolymerization & $\begin{array}{l}\text { The silanization of clay on a PPy/Ag surface was } \\
\text { discussed }\end{array}$ & [139] \\
\hline \multirow{3}{*}{$\mathrm{PEDOT} / \mathrm{TiO}_{2}$} & \multirow{3}{*}{$\begin{array}{l}\text { Photoelectrochemical } \\
\text { polymerization }\end{array}$} & Role of donor- $\pi$-acceptor sensitizers was described & [140] \\
\hline & & $\begin{array}{l}\text { A new method using aqueous micellar solutions } \\
\text { was shown }\end{array}$ & [141] \\
\hline & & $\begin{array}{l}\text { The effect of light intensity on the oxidation level of } \\
\text { PEDOT was studied }\end{array}$ & [142] \\
\hline
\end{tabular}

Carbon and carbon derivatives such as carbon nanotubes (CNTs), graphene, graphene oxide (GO), and reduced graphene oxide (rGO) are other potential components for the synthesis of nanohybrids (Table 8). Ansari et al. [32] synthesized graphene/PANI nanocomposites using an in situ oxidative polymerization in the presence of CTAB as a surfactant. Graphene nanosheets were uniformly distributed in the PANI matrix with the aid of $\mathrm{CTAB}$, leading to high conductivity and thermal stability 
via the $\pi-\pi$ interactions between graphene and PANI. Notably, $p$-toluenesulfonic acid used as a dopant also contributed the enhanced electrical and thermal properties. Similarly, it is noteworthy that several dopants, such as citric acid [143], 1,5-naphthalene disulfonate, 2-naphthalene sulfonate [144], amaranth, and pyrocatechol violet [145], influence the main structure and properties of nanohybrids.

Many studies have focused on the use of GO or rGO with CPs. For instance, Wang et al. [146] synthesized nanohybrid electrode materials through in situ polymerization of thiophene-grafted GO in the presence of an EDOT monomer and investigated the covalent linking of GO with PEDOT chains. Via the covalent coupling of GO with the 3-position of the thiophene unit, the promotion of the coupling of the EDOT monomer in the 2-, 5-positions of the thiophene unit reduced undesirable coupling.

Exfoliation of graphite by CPs may be an efficient strategy for functionalization of graphene with CPs [147]. This method is more beneficial than the conventional approach due to the high electrical conductivity of pure graphene layers. As can be seen in Figure 9, a notable recent work reported the fabrication of free-standing flexible graphene/PANI multilayered nanostructure (GPMN) films via simple physical intercalation of CP into graphite [45]. The resulting nanohybrids not only showed excellent electrochemical performance, they also exhibited high dispersion stability in N-methyl-2-pyrrolidone (NMP) and water for more than three months at room temperature.

a)

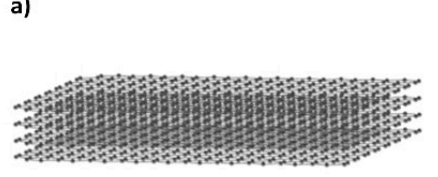

Graphite

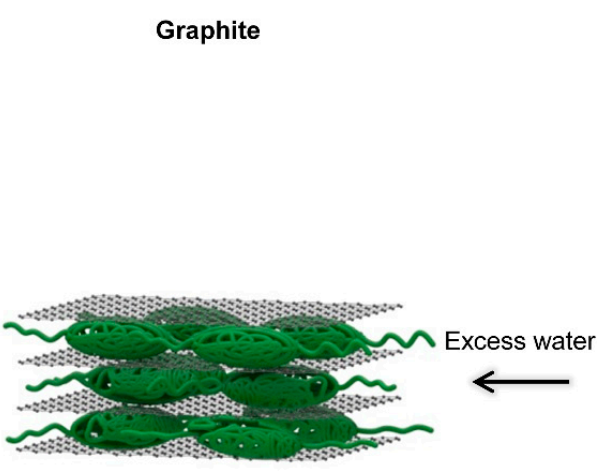

Stable GPMN-W dispersion

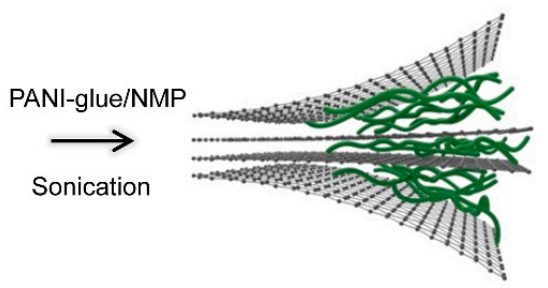

Graphite exfoliation by

Sonication $\downarrow \begin{gathered}\text { Continuous } \\ \text { PANI } \\ \text { intercalation }\end{gathered}$

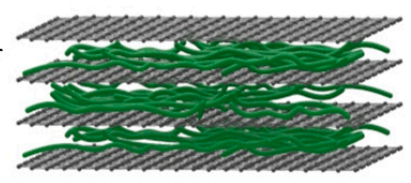

Stable GPMN-N dispersion PANI chains

b)

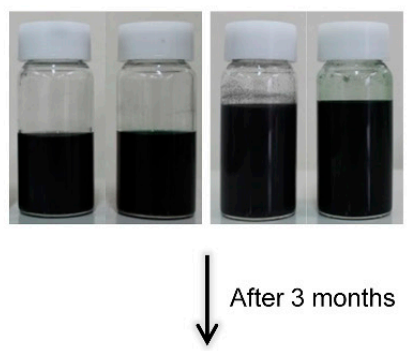

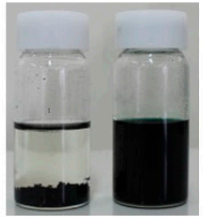

GPMN-N

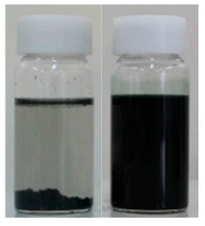

GPMN-W
Figure 9. (a) Schematic illustration of the formation of graphene/PANI multilayered nanostructures (GPMNs) by direct physical exfoliation of graphite with PANI glue; (b) Photographs showing the long-term colloidal stability of the GPMN dispersion solution in the absence (left) and the presence (right) of PANI glue. GPMNs showed outstanding colloidal stability in both $N$-methyl-2-pyrrolidone (NMP) and water. Reprinted with permission from [45]. Copyright 2015, John Wiley \& Sons. 
Table 8. Representative examples of studies where carbon nanomaterials were incorporated into CPs.

\begin{tabular}{|c|c|c|c|c|}
\hline Carbon & $\mathrm{CP}$ & Preparation method & Details & Refs. \\
\hline \multirow{6}{*}{$\mathrm{GN}^{*}$} & \multirow{4}{*}{ PANI } & In situ polymerization & $\begin{array}{l}\text { A microspherical and porous structure was } \\
\text { fabricated }\end{array}$ & [50] \\
\hline & & Reflux technique & $\begin{array}{l}\text { Complex of PANI and GN for enhancing } \\
\text { charge-transfer ability was reported }\end{array}$ & [148] \\
\hline & & $\begin{array}{l}\text { Sandwiched } \\
\text { GN-mesoporous silica as } \\
\text { template }\end{array}$ & $\begin{array}{l}\text { A novel approach to fabricate mesoporous PANI film } \\
\text { coating on GN }\end{array}$ & [149] \\
\hline & & $\begin{array}{l}\text { Low-temperature in situ } \\
\text { polymerization }\end{array}$ & PANI nanorods were coated on graphene nanomesh & [150] \\
\hline & PPy & $\begin{array}{l}\text { Double-doping } \\
\text { electropolymerization }\end{array}$ & $\begin{array}{l}\text { A good example for anchoring double-doped CP on } \\
\text { GN sheet was given }\end{array}$ & [144] \\
\hline & PEDOT & $\begin{array}{l}\text { Electrochemical } \\
\text { codeposition }\end{array}$ & $\begin{array}{l}\text { The role of SDS surfactant in the incorporation of GN } \\
\text { into PEDOT was studied }\end{array}$ & [38] \\
\hline \multirow{9}{*}{ rGO } & \multirow{2}{*}{ PANI } & In situ reduction & A high-surface-area hybrid was reported & [52] \\
\hline & & $\begin{array}{l}\text { Electrostatic adsorption } \\
\text { synthesis }\end{array}$ & $\begin{array}{l}\text { The thickness was well-controlled by } \mathrm{pH} \\
\text { modification }\end{array}$ & [151] \\
\hline & \multirow{6}{*}{ PPy } & Vacuum filtration method & $\begin{array}{l}\text { The improvement of cycling stability was } \\
\text { demonstrated via the addition of rGO }\end{array}$ & [152] \\
\hline & & $\begin{array}{l}\text { Hydrogen bubble dynamic } \\
\text { template }\end{array}$ & $\begin{array}{l}\text { A general method for fabrication of 3D macroporous } \\
\text { hybrid was studied }\end{array}$ & [153] \\
\hline & & Interfacial polymerization & $\begin{array}{l}\text { The comparison of two different methods was } \\
\text { shown, emphasizing the strength of interfacial } \\
\text { polymerization }\end{array}$ & [154] \\
\hline & & Bioreduction technique & $\begin{array}{l}\text { A new simple, environmentally benign method that } \\
\text { was time- and cost-efficient was developed }\end{array}$ & [155] \\
\hline & & One-step synthesis & A good example of a cathode material was shown & [156] \\
\hline & & Interfacial polymerization & A novel electrode material was developed & [157] \\
\hline & PEDOT & $\begin{array}{l}\text { Fast thermal treatment with } \\
\text { in situ deposition }\end{array}$ & $\begin{array}{l}\text { A good example of a hybrid } \mathrm{CP} \text { for gas sensing was } \\
\text { studied }\end{array}$ & [158] \\
\hline \multirow{2}{*}{ SWCNT } & PANI & $\begin{array}{l}\text { Liquid-liquid interfacial } \\
\text { polymerization }\end{array}$ & $\begin{array}{l}\text { The synthesis and characterization of hybrid thin } \\
\text { films in liquid-liquid interface was first studied }\end{array}$ & [159] \\
\hline & P3HT ** & Diels-Alder ligation & $\begin{array}{l}\text { A facile covalent strategy was developed to address } \\
\text { the bundling issue of CNTs }\end{array}$ & [160] \\
\hline MWCNT & PEDOT:PSS & $\begin{array}{l}\text { Electrochemical } \\
\text { co-deposition }\end{array}$ & $\begin{array}{l}\text { A facile and effective approach for electrode } \\
\text { preparation was reported }\end{array}$ & [54] \\
\hline
\end{tabular}

PEDOT:PSS is a mixture of PEDOT and PSS polymers that provides good processability, such that aqueous dispersions of PEDOT:PSS are commercially available. The coupling of PEDOT:PSS with nickel hydroxide $\mathrm{Ni}(\mathrm{OH})_{2}$ and multi-walled carbon nanotubes (MWCNTs) has also been examined [161]. In this ternary architecture design, various synergistic effects were observed in their application as the electrode material for supercapacitors. First, MWCNTs with relatively low cost, large specific surface areas, and excellent conductivity serve as an ideal conductive template for $\mathrm{Ni}(\mathrm{OH})_{2}$ deposition. Second, instead of crystalline $\mathrm{Ni}(\mathrm{OH})_{2}$, which is commonly used as a pseudocapacitive material, amorphous $\mathrm{Ni}(\mathrm{OH})_{2}$ was chosen because structural disorders in $\mathrm{Ni}(\mathrm{OH})_{2}$ can greatly improve the electrochemical efficiency. Finally, wrapping the MWCNT/Ni(OH $)_{2}$ with PEDOT:PSS significantly reduced the contact resistance among the metal oxide/hydroxide-deposited MWCNTs. Another interesting result of this ternary system was proposed by Ramasamy et al. [162], where an effective and simple route for fabricating a ternary nanohybrid via the combination in situ polymerization and electrodeposition method was presented. These examples share similar attributes in the sense that an external component (either a metal-based semiconductor, a nano-carbon, or CPs) is introduced to 
assist the fabrication of the ternary $\mathrm{CP}$ nanohybrids. A partial summary of recent research is shown in Table 9; there are a wealth of examples illustrating the fabrication of ternary hybrids.

Table 9. Representative examples of ternary CP nanohybrids.

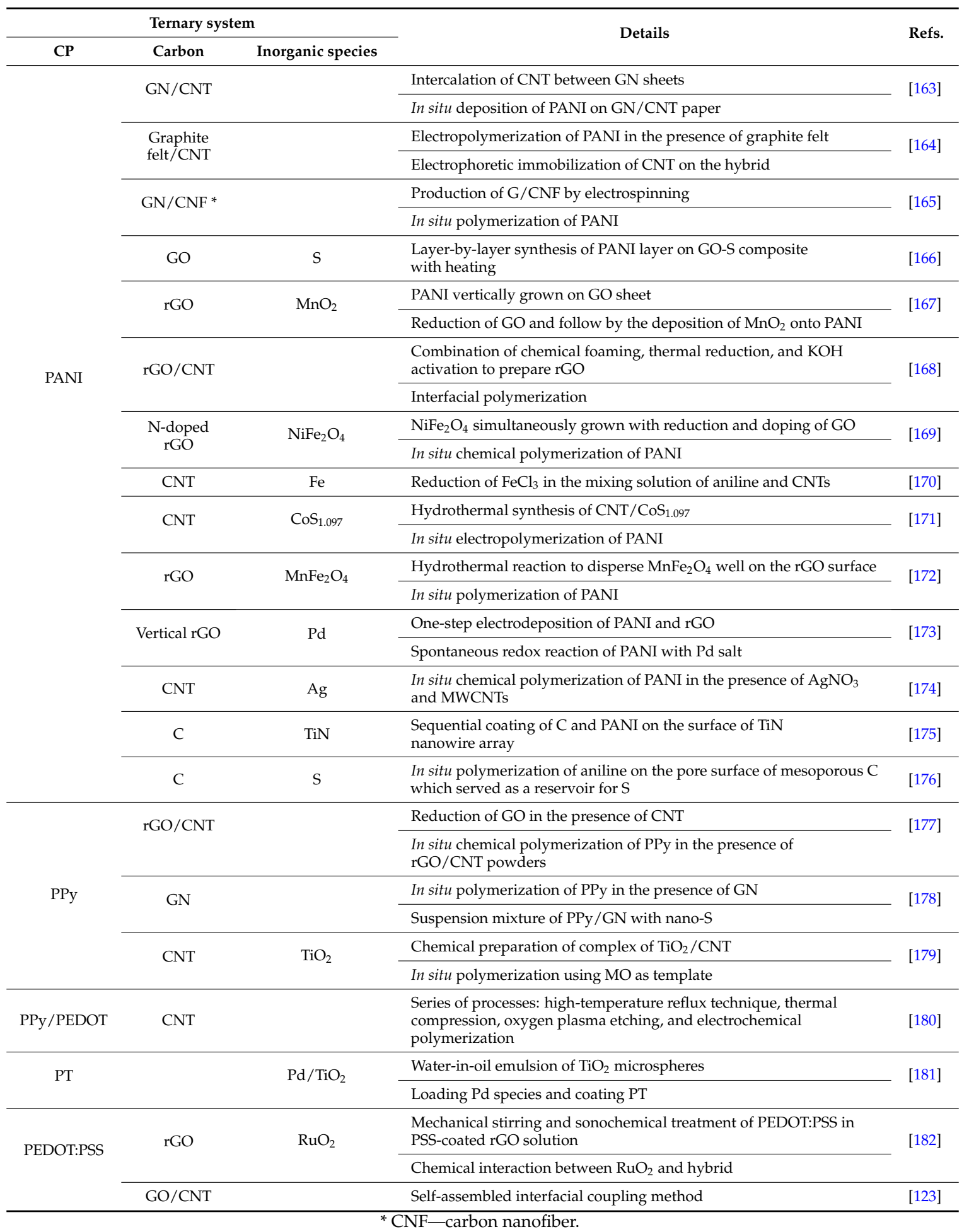

Interestingly, PEDOT:PSS has been employed as a dopant for graphene films. For example, Lee et al. [183] developed the so-called "doping transfer" approach, providing a unique solution to the residue problem of the PMMA-assisted method in graphene substrate transfer (Figure 10). There 
were two interesting points reported. First, the addition of a PEDOT:PSS layer decreased the optical transmittance value by only $1 \%$. This was attributed to the following effects: (i) the strong cohesion between PEDOT:PSS and the graphene film due to the strong attraction between the sulfonic acid group of PSS and graphene, and (ii) the increased cohesion within the PEDOT:PSS layer, which was ascribed to the cross-linking effect of the PSS chains during processing. Second, the doping effect of PEDOT:PSS on graphene can be accomplished via the following three mechanisms: (i) the attraction of electrons from the graphene to the PSS chains, (ii) charge-transfer doping due to electron transfer from graphene to PEDOT:PSS by a difference in the work function; and (iii) percolation doping, which bypasses the charge through the conductive film across resistive grain boundaries in the graphene. Furthermore, doping stability was also achieved through the environmental stability of PEDOT:PSS and the chemical robustness of graphene. Finally, the benefits of the simplified process, the enhanced purity, and the stable doping effect made it possible to generate reliable and versatile graphene/CP nanohybrids.

a)

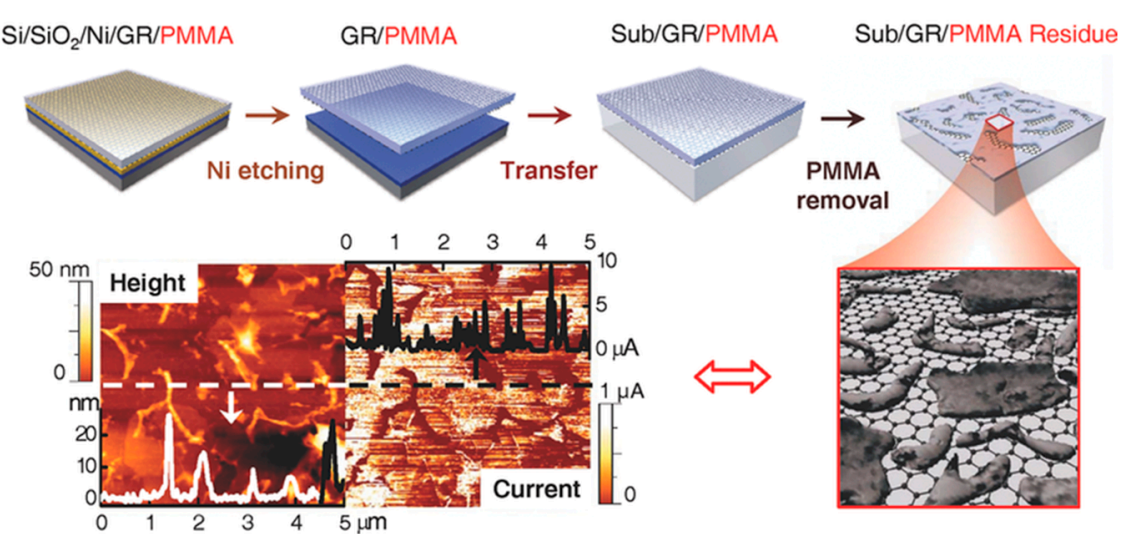

b) $\mathrm{Si} / \mathrm{SiO}_{2} / \mathrm{Ni} / \mathrm{GR} / \mathrm{PEDOT}: \mathrm{PSS}$
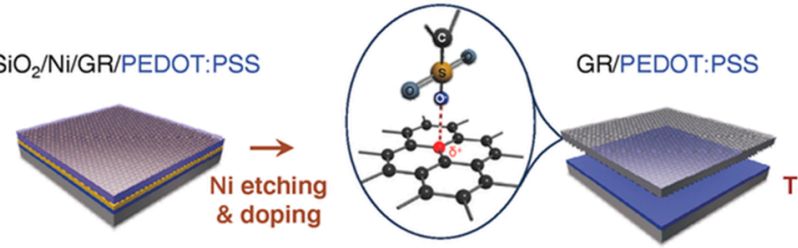

SUb/GR/PEDOT:PSS
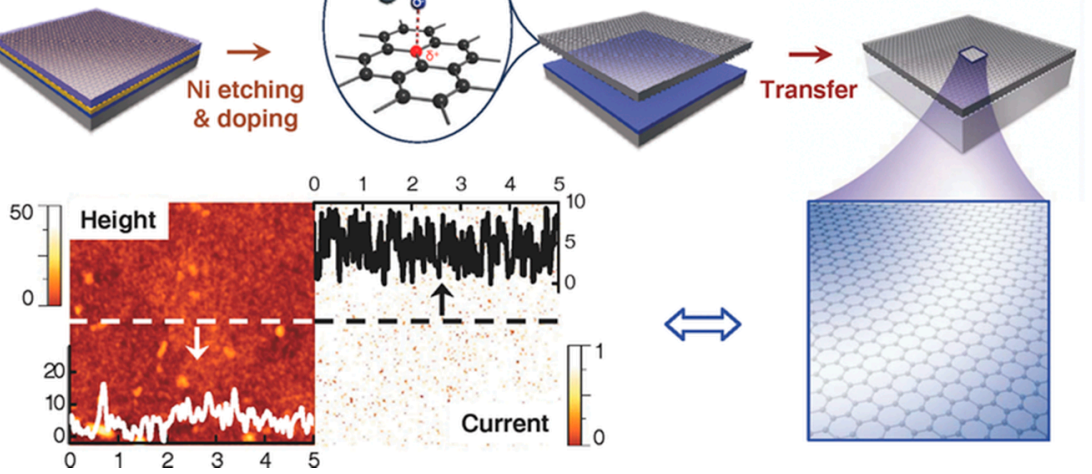

Figure 10. Schematic illustrations and representative conductive AFM analysis for (a) conventional transfer and (b) "doping transfer" methods. PMMA and PEDOT:PSS were used as the support films in both methods. Reprinted with permission from [183]. Copyright 2014, John Wiley \& Sons Inc.

\section{Selected Applications of CP Nanomaterials}

Polymers have advantages over metals or inorganic semiconductors, such as easy synthesis and processing, chemical and structural diversity, low weight, and flexibility. CPs have provided further advantages arising from the inherent $\pi$-electron-conjugated system, which has made it possible to develop many competitive applications in various fields, such as sensors, energy conversion/storage devices, and drug carriers. 


\subsection{Sensors}

A great deal of effort has been made to develop various types of CP-based sensors [4,6,8,101,184-186]. The signal transduction mechanism of CPs for sensor applications has mostly relied on changes in the electrical properties. Recently, there has been an effort to use multiple signal transduction mechanisms to obtain more accurate information on the target species. Zhong et al. [186] designed a gas sensor based on conductive opal photonic crystal films. CPs were deposited into the void spaces of silica colloidal crystal templates. The subsequent silica etching resulted in an inverse opal structure. Upon exposure to ammonia gas, both electrical and optical signals were successfully monitored using the conductive photonic crystal film, which allowed for enhanced response time and accuracy.

Another critical issue in $\mathrm{CP}$ sensors is that it is very difficult for $\mathrm{CP}$ sensors to achieve high selectivity for specific target species. Commonly, many data are collected from a sensor array, and then statistical tools such as principal component analysis for data processing are utilized to evaluate the selectivity of the sensor. This approach was well demonstrated by a recent study using PPy-coated cellulose papers as the sensing material (Figure 11) [187]. PPy/cellulose papers with different oxidation levels were prepared at different applied potentials, and their ability to electrochemically recognize metal ions was systematically investigated. Unique signal patterns were observed for $\mathrm{Hg}(\mathrm{II}), \mathrm{Ag}(\mathrm{I})$, and $\mathrm{Cr}$ (III) through principal component analysis of the response dataset, which support the potential for using the PPy/cellulose paper as a high-selectivity sensor for detecting the three metal ions.

It is also challenging to develop simple, inexpensive, and large-area processing techniques for fabricating nanostructured sensor devices. Electrodeposition can be a good candidate technique to satisfy those requirements. For example, Ferrala et al. [188] achieved the rapid electrophoretic assembly of nanostructured PANI on a gap between microelectrodes by applying an alternating current electric field. A significant benefit is the short assembly time (approximate 5-10 s), despite the fact that electrode gaps are micrometer-sized. The combination of forces such as dielectrophoresis, alternate current electro-osmotic flow, and induced-charge electrokinetic flow, speeded up the assembly process. Consequently, the nanostructured PANI-based sensors exhibited excellent reversibility to low concentrations (a few ppm) of ammonia gas at room temperature, even after storage in air, as well as high sensitivity.

Remarkably, the field-effect transistor (FET) configuration has been used to achieve enhanced sensitivity. Receptor-modified CP nanomaterials are deposited as a channel bridging the source and drain electrodes. When the receptor recognizes a target species, the gate potential being applied on the channel changes, which in turn modulates the source-drain current. With this operating mechanism, many different types of FET sensors have been developed to detect glucose [189], odorants [190], proteins [191,192], and hormones [193]. Recently, a high-performance dopamine FET sensor was successfully demonstrated using human dopamine receptor-containing nanovesicles as the gate-potential modulator on a PEDOT nanotube channel (Figure 12) [184]. The lowest detection level was as low as $10 \mathrm{pM}$, which was 10 times more sensitive than that of previously reported CP-based dopamine sensors. 

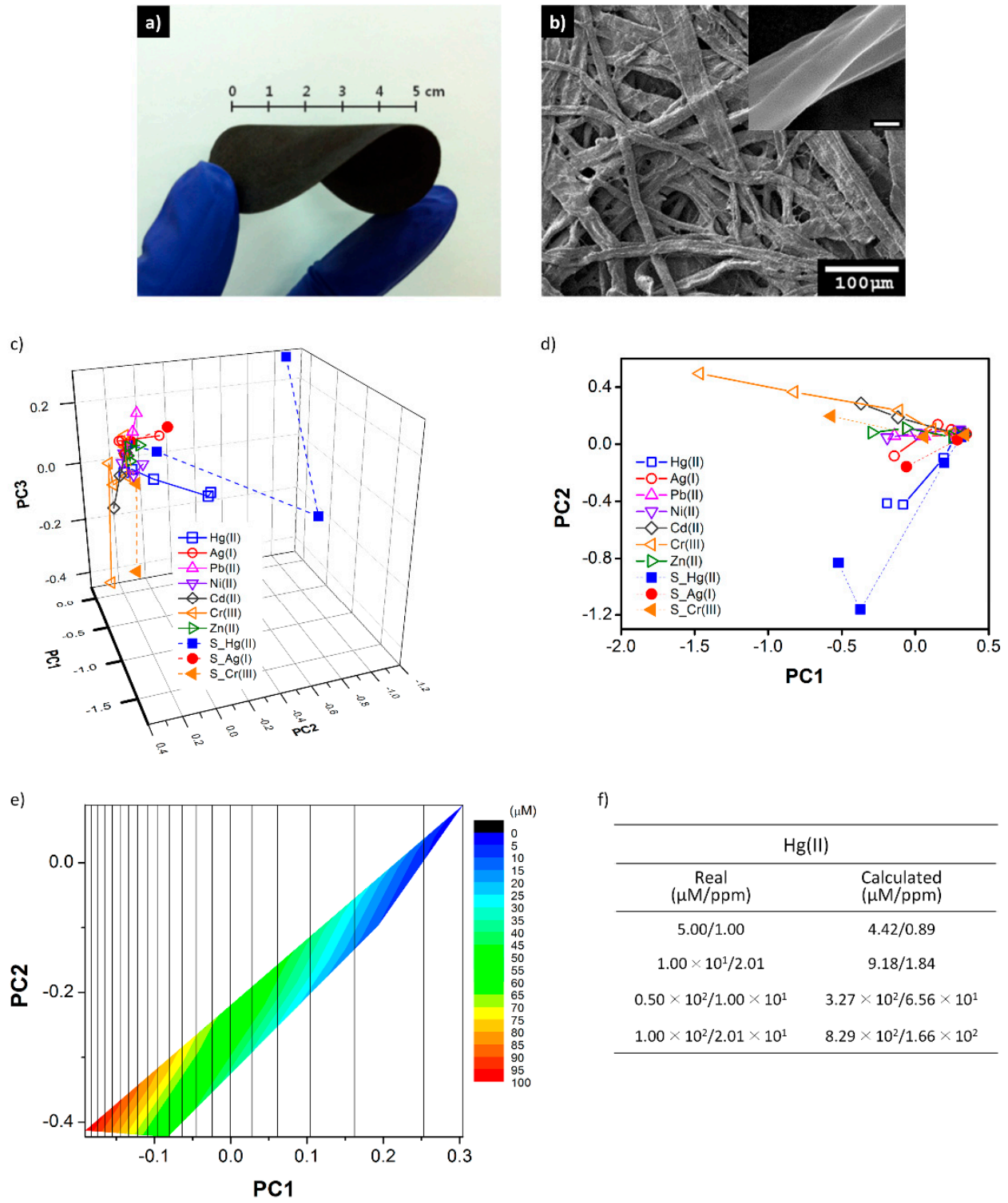

f)

\begin{tabular}{cc}
\hline \multicolumn{2}{c}{$\mathrm{Hg}(\mathrm{II})$} \\
\hline $\begin{array}{c}\text { Real } \\
(\mu \mathrm{M} / \mathrm{ppm})\end{array}$ & $\begin{array}{c}\text { Calculated } \\
(\mu \mathrm{M} / \mathrm{ppm})\end{array}$ \\
\hline $5.00 / 1.00$ & $4.42 / 0.89$ \\
$1.00 \times 10^{1} / 2.01$ & $9.18 / 1.84$ \\
$0.50 \times 10^{2} / 1.00 \times 10^{1}$ & $3.27 \times 10^{2} / 6.56 \times 10^{1}$ \\
$1.00 \times 10^{2} / 2.01 \times 10^{1}$ & $8.29 \times 10^{2} / 1.66 \times 10^{2}$ \\
\hline
\end{tabular}

Figure 11. Photograph showing (a) the flexibility of a large-area, freestanding PPy/cellulose paper; (b) SEM images of a PPy/cellulose paper (inset: high-magnification image, the scale bar is $200 \mathrm{~nm}$ ); (c,d) Principal component analysis plots of the responses of PPy/cellulose papers with data from real samples; (e,f) Calculation of $\mathrm{Hg}$ (II) concentration in groundwater. Reprinted with permission from [187]. Copyright 2014, Royal Society of Chemistry.

Surface acoustic wave (SAW)-based sensors are also an interesting approach for gas detection due to their many benefits, such as small size, high sensitivity, and fast and reliable response. Li and coworker [40] spin-coated PPy nanoparticles onto SAW transducers to trace acetone gas. The nanoparticle layer coated onto the $\mathrm{ZnO}$ intermediate layer showed rapid response/recovery times and excellent sensitivity resulting from low gas-diffusion resistance. Additionally, the responses of the sensors were linearly proportional to the acetone concentration in the range from a few to a few tens of ppm. 


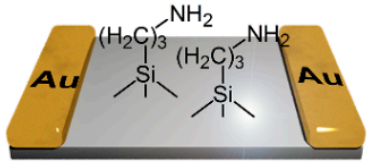

APS-treated IMA substrate

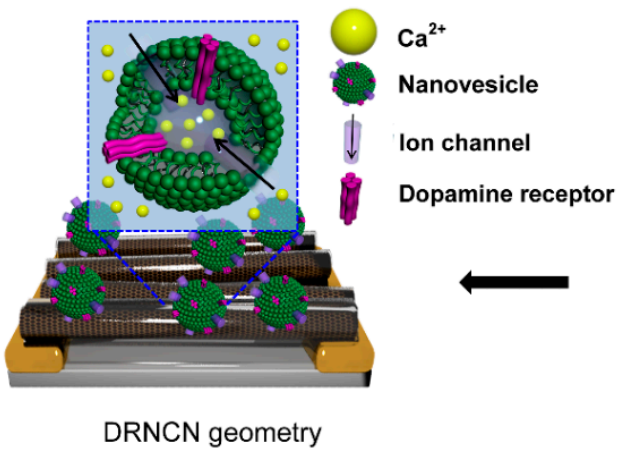

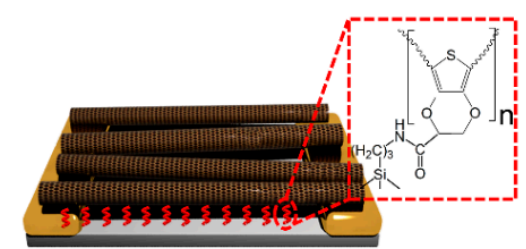

CPEDOT NTs immobilized on IMA

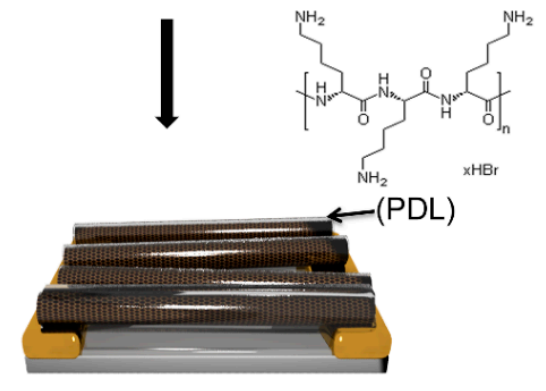

CPEDOT NTs coated with PDL

Figure 12. Schematic illustrations of construction steps for receptor geometry, where IMA, CPEDOT NTs, PDL, and DRNCN note interdigitated microelectrode array, carboxylated PEDOT nanotubes, poly-D-lysine, and dopamine receptor-containing nanovesicles-immobilized CPEDOT NTs, respectively. Reprinted with permission from [184]. Copyrights 2014, Nature Publishing Group.

Among various CPs, application of nanostructured PANIs as sensing materials has been widely explored. Chiam et al. [194] prepared a colorimetric alcohol sensor using PANI-coated glass microfibers with laser light source with a wavelength of $1550 \mathrm{~nm}$. A redshift in the output spectrum was observed via electrostatic interaction between the partial positive amine group of PANI and the partial negative hydroxyl group of alcohol.

\subsection{Electrochemical Energy Storage Devices}

There is an increasing demand for high-performance energy storage devices. A variety of electrode materials have been designed and tested so far, including $\mathrm{CP}$ nanomaterials. As a recent remarkable example, PPy hollow nanoparticles were simply prepared using surfactant templates and their performance as the electrode for electrochemical capacitors was examined (Figure 13) [67]. The hollow nanoparticles served as a nanocage to prevent metal ion leaching during charge/discharge, thus allowing excellent capacitance retention. In addition, pseudocapacitive metal species (e.g., Mn- and Ni-related species) were readily deposited on the inner and outer surfaces of the hollow nanoparticles, providing enhanced capacitances.

It should be noted that control over the microstructure and properties of a material does not guarantee improvement in the material's performance because each material has an intrinsically limited capacitance. Therefore, different kinds of materials have been hybridized to obtain desirable synergistic effects. Typically, graphene/CP nanohybrid electrodes can be used to fabricate high-performance, flexible, solid-state electrochemical capacitors. Very recently, PPy nanospheres were intercalated into stacked graphene layers, which resulted in a unique 3D opened structure that allowed facile electrolyte diffusion [147]. As a result, the nanohybrids had high capacitance, as well as good long-term cycling stability. In addition, importantly, the packing density of the nanohybrids varied with the nanosphere content, indicating the potential for high volumetric capacitance. Similarly, the fabrication of graphene/PANI multilayered nanostructures has been reported [45], in which graphite was physically exfoliated by PANI glue (Figure 14). The physically exfoliated graphene provided much better electrical properties than GO and rGO. The graphene/PANI nanostructure-based electrode 
showed a high specific capacitance of $200 \mathrm{~F} \cdot \mathrm{g}^{-1}$, a cycling stability with capacitance retention of $\sim 80 \%$ after 5000 charge/discharge cycles, and excellent flexibility.

a)
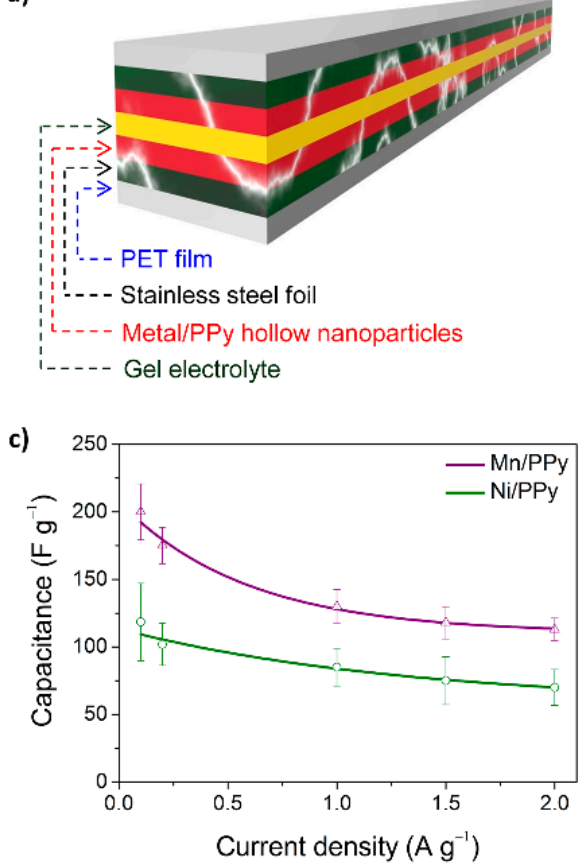
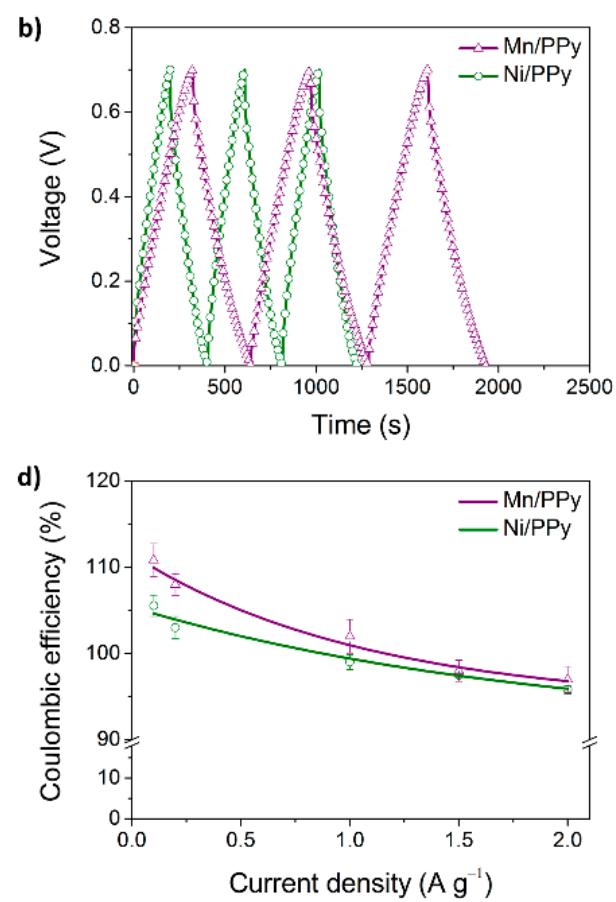

Figure 13. Flexible, all-solid-state cells based on Mn/PPy hollow nanoparticle electrodes. (a) Pictorial representation of an all-solid-state flexible electrochemical capacitor cell; (b) typical galvanostatic charge/discharge curves of metal/PPy hollow nanoparticles measured at a current density of $0.1 \mathrm{~A} \cdot \mathrm{g}^{-1}$; (c) specific capacitances measured at different current densities; and (d) calculated coulombic efficiencies. Reprinted with permission from [67]. Copyright 2015, Nature Publishing Group.

In addition to electrode materials, other components such as additives, electrolytes, and separators can be tailored to provide better device performance. Employing redox-active electrolytes can be a good approach toward enhancement of the pseudocapacitive performance of CPs [195]. Prepared by simply adding a redox mediator to the conventional electrolyte, redox-active electrolytes have shown significant improvements in the specific capacitance of pseudocapacitors using various CPs such as PANI, PPy, and PEDOT as compared to conventional electrolytes. In addition, electrode systems such as symmetric/asymmetric electrode configuration and the weight ratio of two electrodes is also a key factor affecting the performance of the capacitor. Our group well demonstrated the importance of the electrode system in electrochemical capacitors using two different nanohybrid electrode materials, namely, $\mathrm{MnO}_{2}$ / PEDOT nanotubes and $\mathrm{rGO} / \mathrm{CNFs}$ [196]. Lastly, the latest review article addresses major issues in electrochemical capacitor application using nanostructured electrode materials [197]. 
a)

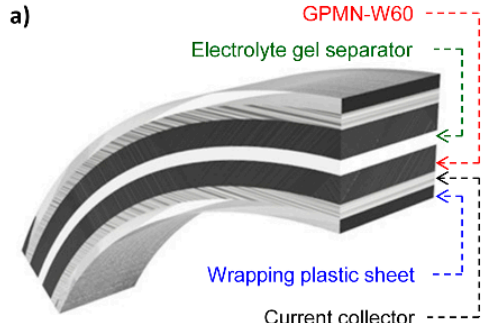

b)

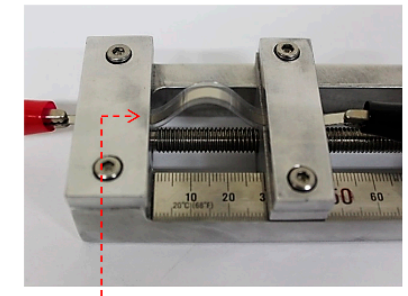

GPMN-based flexible solid-state capacitors
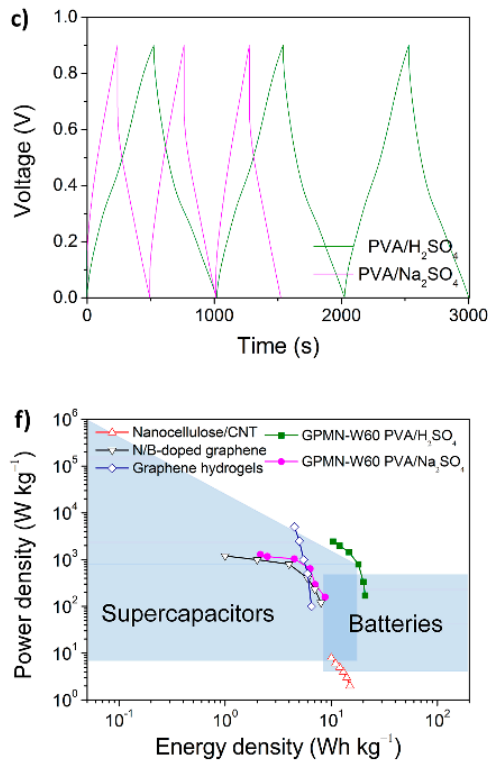

Energy density (Wh kg )
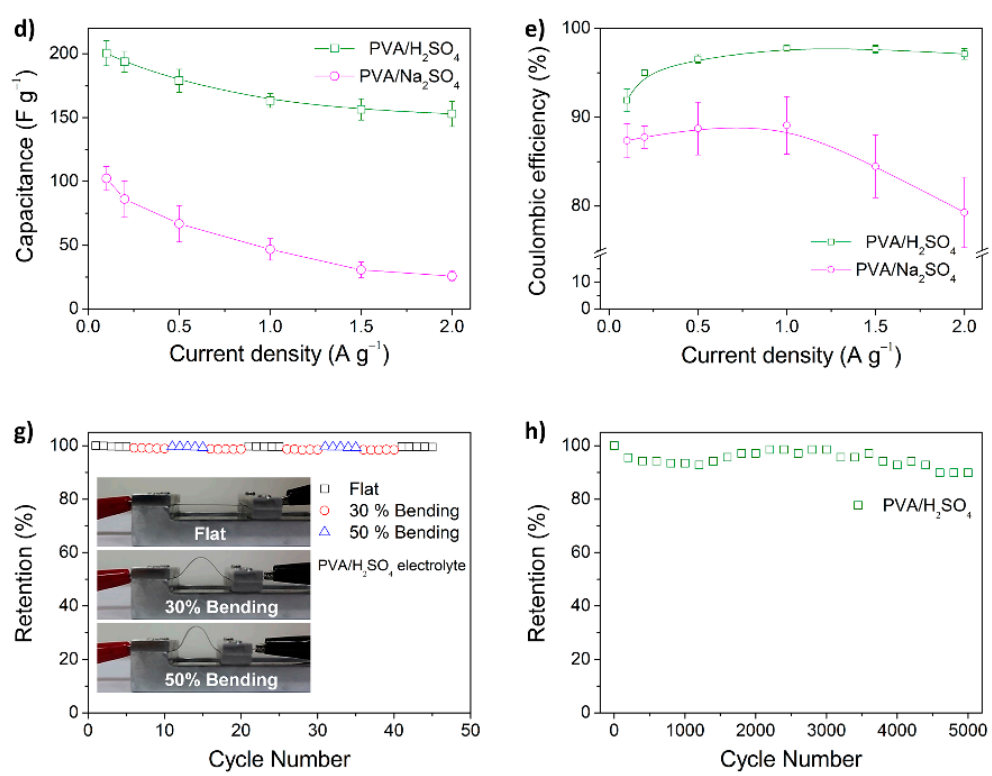

Figure 14. Flexible, all-solid-state graphene/PANI-glue multilayered nanostructure cells: (a) schematic of an all-solid-state flexible electrochemical capacitor cell; (b) typical photograph of cell performance measurement under mechanical deformation; (c) galvanostatic charge-discharge curves at a current density of $0.1 \mathrm{~A} \cdot \mathrm{g}^{-1}$ for different electrolytes; (d) specific capacitances as a function of current density; (e) coulombic efficiency as a function of current density; (f) Ragone plots; (g) capacitance as a function of bend radii; and (h) long-term cycling stability of the cell with an acidic electrolyte. Reprinted with permission from [45]. Copyright 2015, John Wiley \& Sons Inc.

\subsection{Photovoltaic Cells}

Dye-sensitized solar cells (DSSCs) have become popular for various energy conversion applications. A typical DSSC consists of a transparent photo-anode with a dye-sensitized mesoporous thin film, a redox couple, and a counter electrode with a catalytic layer deposited on a fluorine-doped tin-oxide (FTO) substrate $[17,37,48,142,162,180,198-200]$. Recently, much attention has been paid to CPs as a relatively low-cost device for photovoltaic application due to their excellent electrocatalytic activity, high electrical conductivity, and good film-forming ability [198,201]. For example, Kung et al. [198] examined a PEDOT hollow microflower array film as the catalytic material on the counter electrode of a DSSC. The PEDOT hollow microflower arrays contributed to a high power conversion efficiency of $7.20 \%$, which was comparable to that of a cell with a sputtered Pt film (7.61\%). Considering the low value of the Warburg diffusion resistance of the DSSC, it was believed that the unique microflower structure would facilitate a kind of hemispherical diffusion of ions for the electrocatalytic reaction in the electrolyte region. The lower the Warburg diffusion resistance of the DSSC, the higher the fill factor of the cell (a critical parameter for evaluation of the cell performance). Lin et al. [180] reported the effect of PEDOT coating on the electrocatalytic activity of CNT/polypropylene plates. Interestingly, it was found that the PEDOT-coated CNT/polypropylene plate showed a Pt-like electrocatalytic activity for 
$\mathrm{I}_{3}{ }^{-}$reduction. Consequently, a DSC with the PEDOT-coated CNT/polypropylene counter electrode showed a high power conversion efficiency of $6.77 \%$, even after the bending test.

From a survey of numerous studies, it can be confirmed that the application of $\mathrm{CP}$ nanomaterials as potential substitutes for Pt counter electrodes in DSSCs is a recent trend. Nevertheless, a clear mechanism to describe the function of $\mathrm{CP}$ nanomaterials as counter electrode materials still needs to be clarified. It is anticipated that the use of nanostructured CPs will open a new avenue for industrial fabrication of DSSCs due to their low cost and reasonable performance as compared to $\mathrm{Pt}$ electrodes [199].

\subsection{Drug Carriers}

Recently, there has been substantial effort to fabricate drug delivery systems based on smart materials [73]. CPs that possess ion-exchange properties are being studied as promising materials for drug reservoirs for this purpose. In contrast to physical entrapment, CPs exhibit reversible electrostatic immobilization. The mechanism of this process relies on the fact that CPs undergo a charging-discharging process and adopt positive/negative charges, which strongly depend on their oxidation state. These charges attract ions of the opposite charge in the polymeric matrix, linking them via coulombic interactions. Hence, $\mathrm{CPs}$ can immobilize anionic drugs during oxidation (doping), move to a target site, and release the drug via the process of reduction (dedoping).

In a trial of a drug delivery solution for anticancer treatment, Krukiewicz et al. [202] fabricated a robust and low-cost nanocomposite based on PEDOT and oleanolic acid. The materials exhibited competitive characteristics such as good biological activity of the embedded drug and well-controlled release, making it a potential candidate for further development and a promising commercial application. Hong et al. [203] proposed an integrated strategy with conductive disulfide-biotin-doped PPy nanowires for cell capture, on-demand release, and in situ quantification of captured cells within the same platform. The PPy nanowire platform showed very high sensitivity and specificity. In addition, the enzymatic reduction of hydrogen peroxide on PPy resulted in a greatly increased amperometric response with a wide range and low limit of detection. Interestingly, this helps us to achieve a better understanding of circulating tumor cells, with the aim of unraveling the complex mechanisms governing cancer biology.

Although the mechanisms of CP-based drug carriers are very attractive due to the inherent doping-dedoping and stimulus-responsive properties of CPs (where drugs can be incorporated into polymer chains as doping agents and then released through electrical stimulation), the capacity of drug loading is usually low because it is strongly dependent on the doping level. Furthermore, the types of drugs that can be used are limited to charged and small molecules. Therefore, a limited range of drugs and relatively low drug-loading capacities are two main drawbacks for the practical application of CP-based drug delivery systems. In order to partly solve those problems, Jiang et al. [106] found that nano- or micro-sized inter-nanowire pores of a PPy nanowire network can serve as reservoirs to store drugs. In addition, it is not necessary to consider the volume and the charge of the loaded drugs because the space for drug storage has been changed from the backbones of the CPs to the vacancies among the nanowires. Consequently, both the range of loaded drugs and the drug-loading capacity can be effectively improved. Herein, a PPy film was further deposited on top of a PPy nanowire network by chemical vapor deposition to inhibit leaking of the stored drugs (Figure 15). 


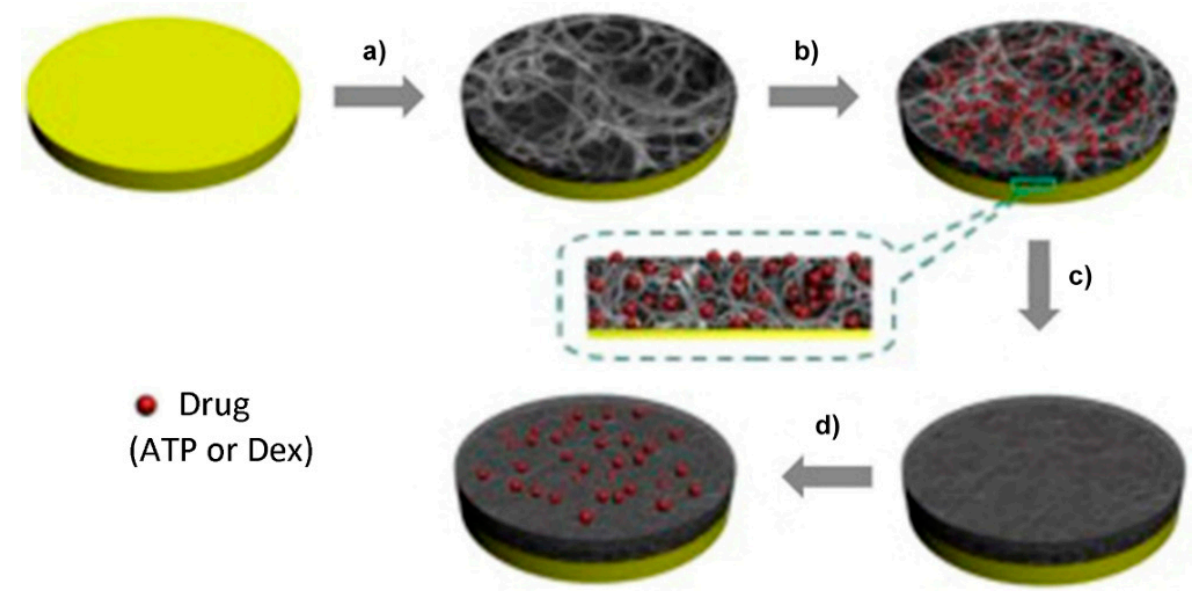

Figure 15. Schematic process showing the fabrication and drug release of the drug-loaded PPy nanowire network coated by a PPy film: (a) electropolymerized PPy nanowire network; (b) addition of the drug; (c) preparation of the PPy film by CVD; (d) application of electrical stimulation to release drug. Reprinted with permission from [106]. Copyright 2013, Elsevier.

\section{Conclusions and Outlook}

To date, an enormous number of approaches have been developed to fabricate $\mathrm{CP}$ nanomaterials. The goal of this review article was to better illustrate the recent advances in the synthesis of $\mathrm{CP}$ nanomaterials and their potential applications. CP nanohybrids are also promising candidates because they show interesting properties not observed in the individual components and their bulk counterparts. There is no doubt that the hybridization of CPs on a nanoscale offers a very broad and promising "toolbox" for research, not only to solve the abovementioned challenges and enhance the corresponding properties, but also to achieve multifunctional nanosystems. However, an easy, efficient, and scalable synthesis method for nanostructured CPs with desirable sizes, microstructures, and properties is still in demand. Furthermore, there are still limitations in the application of nanoscale devices, such as reproducibility, stability of the properties of CPs, and control of individual nanostructures.

Specifically, in terms of the major properties, there are several critical challenges in achieving further advances in $\mathrm{CP}$ research: (i) metallic conductivity; (ii) processability; and (iii) environmental stability. First, the common explanation of the conductive mechanism of CPs is suggested by the Drude model: charge carriers hop between ordered metallic domains instead of unordered amorphous domains $[26,107,204]$. Thus, a high degree of structural order would lead to high electrical conductivity. However, there are no effective methods to characterize and control the crystalline/amorphous ratio of $\mathrm{CPs}$, particularly in hybrid systems. This might be the reason why most studies have not focused on the crystalline properties of CPs for achieving metal-like electrical properties. Doping is an essential step for the preparation of CPs. During the last decade, it has been believed that APS and metal salts (e.g., $\left.\mathrm{FeCl}_{3}, \mathrm{Fe}_{2}\left(\mathrm{SO}_{4}\right)_{3}\right)$ are the best oxidants; acids such as $\mathrm{HCl}$ and $\mathrm{H}_{2} \mathrm{SO}_{4}$ are the common doping agents, in which sulfonic acids such as dodecylbenzenesulfonic acid and camphorsulfonic acid contribute to improvement in the solubility of CPs; and some anionic surfactants are not only molecular templates but also doping agents. More sophisticated doping techniques, such as dual doping, double doping, and triple doping, have also been developed to provide desirable properties and functions to CPs, including metal-like conductivity and water-solubility. However, it should be also noted that the more complex the doping step, the harder it is to control and predict the major characteristics of the resulting $\mathrm{CP}$ nanomaterials. In general, $\mathrm{CPs}$ are insoluble in common solvents and are not thermoplastic, which has prevented a wide range of application of CPs. As a representative commercialized soluble $\mathrm{CP}$, many researchers have used PEDOT:PSS. Another important issue is that the coupling of PEDOT with PSS enhances the environmental stability of PEDOT's properties. In fact, PEDOT was initially 
developed to provide a soluble conducting polymer that lacked the presence of undesired $\alpha, \beta$ - and $\beta, \beta$-coupling of thiophene rings within the polymer backbone [205]. However, the resulting PEDOT was still insoluble, although it fortunately showed stability and high conductivity. PEDOT became soluble in water when blended with a polyelectrolyte PSS. This story about PEDOT:PSS may be a good model for developing processable CPs with stable properties. Of course, combining CPs with PSS cannot be a generalized solution. More efforts should be aimed at designing and synthesizing new monomers and dopants.

Inspired by the Nobel Prize in 2000, numerous researchers have been devoted to CP research. Although the tremendous value of $\mathrm{CP}$ nanomaterials is obvious, we believe that their full potential is yet to be realized. Facilitating interdisciplinary research will provide new opportunities for $\mathrm{CP}$ nanomaterials, and the intelligent integration of the numerous advantages of CPs with other materials has been and will continue to be a key topic in various applications. It is highly anticipated that further advances in CPs will lead to new horizons in material technology and its application.

Acknowledgments: This research was supported by the National Research Foundation of Korea (NRF) funded by the Korea government (MSIP) (NRF-2015R1A2A2A01007166).

Author Contributions: Hyeonseok Yoon conceived the topic and designed the overall structure of the article; Duong Nguyen Nguyen reviewed the literature; Duong Nguyen Nguyen and Hyeonseok Yoon co-wrote the article.

Conflicts of Interest: The authors declare no conflict of interest.

\section{References}

1. Xia, L.; Wei, Z.; Wan, M. Conducting polymer nanostructures and their application in biosensors. J. Colloid Interface Sci. 2010, 341, 1-11. [CrossRef] [PubMed]

2. Long, Y.Z.; Li, M.M.; Gu, C.; Wan, M.; Duvail, J.L.; Liu, Z.; Fan, Z. Recent advances in synthesis, physical properties and applications of conducting polymer nanotubes and nanofibers. Prog. Polym. Sci. 2011, 36, 1415-1442. [CrossRef]

3. Yin, Z.; Zheng, Q. Controlled synthesis and energy applications of one-dimensional conducting polymer nanostructures: An overview. Adv. Energy Mater. 2012, 2, 179-218. [CrossRef]

4. Yoon, H. Current trends in sensors based on conducting polymer nanomaterials. Nanomaterials 2013, 3, 524-549. [CrossRef]

5. Janáky, C.; Rajeshwar, K. The role of (photo)electrochemistry in the rational design of hybrid conducting polymer/semiconductor assemblies: From fundamental concepts to practical applications. Prog. Polym. Sci. 2015, 43, 96-135. [CrossRef]

6. Park, S.; Kwon, O.; Lee, J.; Jang, J.; Yoon, H. Conducting polymer-based nanohybrid transducers: A potential route to high sensitivity and selectivity sensors. Sensors 2014, 14, 3604-3630. [CrossRef] [PubMed]

7. Yoon, H.; Choi, M.; Lee, K.J.; Jang, J. Versatile strategies for fabricating polymer nanomaterials with controlled size and morphology. Macromol. Res. 2008, 16, 85-102. [CrossRef]

8. Yoon, H.; Jang, J. Conducting-polymer nanomaterials for high-performance sensor applications: Issues and challenges. Adv. Funct. Mater. 2009, 19, 1567-1576. [CrossRef]

9. Deng, J.; Wang, X.; Guo, J.; Liu, P. Effect of the oxidant/monomer ratio and the washing post- treatment on electrochemical properties of conductive polymers. Ind. Eng. Chem. Res. 2014, 53, 13680-13689. [CrossRef]

10. Tantawy, H.R.; Weakley, A.T.; Aston, D.E. Chemical effects of a solvent-limited approach to HCl-doped polyaniline nanopowder synthesis. J. Phys. Chem. C 2013, 118, 1294-1305. [CrossRef]

11. Mu, J.; Ma, G.; Peng, H.; Li, J.; Sun, K.; Lei, Z. Facile fabrication of self-assembled polyaniline nanotubes doped with d-tartaric acid for high-performance supercapacitors. J. Power Sources 2013, 242, 797-802. [CrossRef]

12. Lu, Q.; Zhao, Q.; Zhang, H.; Li, J.; Wang, X.; Wang, F. Water dispersed conducting polyaniline nanofibers for high-capacity rechargeable lithium-oxygen battery. ACS Macro Lett. 2013, 2, 92-95. [CrossRef]

13. Lu, S.; Zhang, X.; Feng, T.; Han, R.; Liu, D.; He, T. Preparation of polypyrrole thin film counter electrode with pre-stored iodine and resultant influence on its performance. J. Power Sources 2015, 274, 1076-1084. [CrossRef] 
14. Severt, S.Y.; Ostrovsky-Snider, N.A.; Leger, J.M.; Murphy, A.R. Versatile method for producing 2D and 3D conductive biomaterial composites using sequential chemical and electrochemical polymerization. ACS Appl. Mater. Interfaces 2015, 7, 25281-25288. [CrossRef] [PubMed]

15. Lee, S.B.; Lee, S.M.; Park, N., II; Lee, S.; Chung, D. Preparation and characterization of conducting polymer nanocomposite with partially reduced graphene oxide. Synth. Met. 2015, 201, 61-66. [CrossRef]

16. Feng, W.; Wan, A.S.; Garfunkel, E. Interfacial bonding and morphological control of electropolymerized polythiophene films on ZnO. J. Phys. Chem. C 2013, 117, 9852-9863. [CrossRef]

17. Zhang, X.; Wang, S.; Lu, S.; Su, J.; He, T. Influence of doping anions on structure and properties of electro-polymerized polypyrrole counter electrodes for use in dye-sensitized solar cells. J. Power Sources 2014, 246, 491-498. [CrossRef]

18. Chen, S.; Zhitomirsky, I. Polypyrrole electrodes doped with sulfanilic acid azochromotrop for electrochemical supercapacitors. J. Power Sources 2013, 243, 865-871. [CrossRef]

19. McGarry, S.P.; Barrera Ramirez, E.A.; Tarr, N.G. Modelling electrochemical control of percolation conductivity in short-chain templated conducting polymers. Synth. Met. 2015, 200, 156-163. [CrossRef]

20. Sangermano, M.; Sordo, F.; Chiolerio, A.; Yagci, Y. One-pot photoinduced synthesis of conductive polythiophene-epoxy network films. Polymer 2013, 54, 2077-2080. [CrossRef]

21. Yamada, K.; Yamada, Y.; Sone, J. Three-dimensional photochemical microfabrication of poly(3,4-ethylenedioxythiophene) in transparent polymer sheet. Thin Solid Films 2014, 554, 102-105. [CrossRef]

22. Janáky, C.; Chanmanee, W.; Rajeshwar, K. Mechanistic aspects of photoelectrochemical polymerization of polypyrrole on a $\mathrm{TiO}_{2}$ nanotube array. Electrochim. Acta 2014, 122, 303-309. [CrossRef]

23. Ngaboyamahina, E.; Cachet, H.; Pailleret, A.; Sutter, E.M.M. Photo-assisted electrodeposition of an electrochemically active polypyrrole layer on anatase type titanium dioxide nanotube arrays. Electrochim. Acta 2014, 129, 211-221. [CrossRef]

24. Su, P.G.; Peng, Y.T. Fabrication of a room-temperature $\mathrm{H}_{2} \mathrm{~S}$ gas sensor based on $\mathrm{PPy} / \mathrm{WO}_{3}$ nanocomposite films by in-situ photopolymerization. Sen. Actuators B Chem. 2014, 193, 637-643. [CrossRef]

25. Guimard, N.K.; Gomez, N.; Schmidt, C.E. Conducting polymers in biomedical engineering. Polym. Biomed. Appl. 2007, 32, 876-921.

26. Terje, A.; Skotheim, J.R.R. Conjugated Polymers Theory, Synthesis, Properties, and Characterization; CRC Press: Boca Raton, FL, USA, 1993; Volume 1.

27. Babu, K.F.; Senthilkumar, R.; Noel, M.; Kulandainathan, M.A. Polypyrrole microstructure deposited by chemical and electrochemical methods on cotton fabrics. Synth. Met. 2009, 159, 1353-1358. [CrossRef]

28. Sezer, E.; Ustamehmetoglu, B. Chemical and electrochemical polymerisation of pyrrole in the presence of N-substituted carbazoles. Synth. Met. 1999, 107, 7-17. [CrossRef]

29. Gorey, B.; Smyth, M.R.; White, B.; Morrin, A. Fabrication of homogenous three dimensionally ordered conducting polymer-polystyrene opal structures in microfluidic channels. J. Mater. Chem. C 2014, 2, 6004-6009. [CrossRef]

30. Mazzotta, E.; Surdo, S.; Malitesta, C.; Barillaro, G. High-aspect-ratio conducting polymer microtube synthesis by light-activated electropolymerization on microstructured silicon. Electrochem. Commun. 2013, 35, 12-16. [CrossRef]

31. Ovando-Medina, V.M.; Martínez-Gutiérrez, H.; Corona-Rivera, M.A.; Cervantes-González, E.; Flores-Mejía, J.; Farías-Cepeda, L. Silver/silver bromide/polypyrrole nanoparticles obtained by microemulsion photopolymerization in the presence of a cationic surfactant. Colloid Polym. Sci. 2013, 291, 2131-2138. [CrossRef]

32. Ansari, M.O.; Khan, M.M.; Ansari, S.A.; Amal, I.; Lee, J.; Cho, M.H. pTSA doped conducting graphene/polyaniline nanocomposite fibers: Thermoelectric behavior and electrode analysis. Chem. Eng. J. 2014, 242, 155-161. [CrossRef]

33. Zhu, X.; Hou, K.; Chen, C.; Zhang, W.; Sun, H.; Zhang, G.; Gao, Z. Structural-controlled synthesis of polyaniline nanoarchitectures using hydrothermal method. High Perform. Polym. 2014, 27, 207-216. [CrossRef]

34. Stejskal, J.; Sapurina, I.; Trchová, M.; Šeděnková, I.; Kovářová, J.; Kopecká, J.; Prokeš, J. Coaxial conducting polymer nanotubes: Polypyrrole nanotubes coated with polyaniline or poly( $p$-phenylenediamine) and products of their carbonisation. Chem. Pap. 2015, 69, 1341-1349. [CrossRef] 
35. Varga, M.; Kopecká, J.; Morávková, Z.; Křivka, I.; Trchová, M.; Stejskal, J.; Prokeš, J. Effect of oxidant on electronic transport in polypyrrole nanotubes synthesized in the presence of methyl orange. J. Polym. Sci. B Polym. Phys. 2015, 53, 1147-1159. [CrossRef]

36. Dutt, S.; Siril, P.F. Controlling the morphology of polyaniline-platinum nanocomposites using swollen liquid crystal templates. Synth. Met. 2015, 209, 82-90. [CrossRef]

37. Qiu, Y.; Lu, S.; Wang, S.; Zhang, X.; He, S.; He, T. High-performance polyaniline counter electrode electropolymerized in presence of sodium dodecyl sulfate for dye-sensitized solar cells. J. Power Sources 2014, 253, 300-304. [CrossRef]

38. Zhou, H.; Han, G.; Fu, D.; Chang, Y.; Xiao, Y.; Zhai, H.J. Petal-shaped poly(3,4-ethylenedioxythiophene)/ sodium dodecyl sulfate-graphene oxide intercalation composites for high-performance electrochemical energy storage. J. Power Sources 2014, 272, 203-210. [CrossRef]

39. Oh, J.Y.; Shin, M.; Lee, J.B.; Ahn, J.H.; Baik, H.K.; Jeong, U. Effect of PEDOT nanofibril networks on the conductivity, flexibility, and coatability of PEDOT:PSS films. ACS Appl. Mater. Interfaces 2014, 6, 6954-6961. [CrossRef] [PubMed]

40. Li, F.; Li, H.; Jiang, H.; Zhang, K.; Chang, K.; Jia, S.; Jiang, W.; Shang, Y.; Lu, W.; Deng, S.; et al. Polypyrrole nanoparticles fabricated via Triton X-100 micelles template approach and their acetone gas sensing property. Appl. Surf. Sci. 2013, 280, 212-218. [CrossRef]

41. Wan, M. A template-free method towards conducting polymer nanostructures. Adv. Mater. 2008, 20, 2926-2932. [CrossRef]

42. Charlot, B.; Sassine, G.; Garraud, A.; Sorli, B.; Giani, A.; Combette, P. Micropatterning PEDOT:PSS layers. Microsyst. Technol. 2013, 19, 895-903. [CrossRef]

43. Kannan, B.; Williams, D.E.; Laslau, C.; Travas-Sejdic, J. The electrochemical growth of highly conductive single PEDOT (conducting polymer):BMIPF6 (ionic liquid) nanowires. J. Mater. Chem. 2012, 22, 18132-18135. [CrossRef]

44. Cardenas, J.R.; de Franca, M.G.O.; de Vasconcelos, E.A.; de Azevedo, W.M.; da Silva, E.F., Jr. Growth of sub-micron fibres of pure polyaniline using the electrospinning technique. J. Phys. D Appl. Phys. 40 2007, 40, 1068-1071. [CrossRef]

45. Choi, H.; Ahn, K.J.; Lee, Y.; Noh, S.; Yoon, H. Free-Standing, multilayered graphene/polyaniline-glue/ graphene nanostructures for flexible, solid-state electrochemical capacitor application. Adv. Mater. Interfaces 2015, 2. [CrossRef]

46. Wang, A.; Xu, H.; Feng, J.; Ding, L.; Tong, Y.; Li, G. Design of Pd/PANI/Pd sandwich-structured nanotube array catalysts with special shape effects and synergistic e ff ects for ethanol electrooxidation. J. Am. Chem. Soc. 2013, 135, 10703-10709. [CrossRef] [PubMed]

47. Guzelturk, B.; Menk, F.; Philipps, K.; Kelestemur, Y.; Olutas, M.; Zentel, R.; Demir, H.V. Colloidal nanoplatelet/conducting polymer hybrids: excitonic and material properties. J. Phys. Chem. C 2016, 120, 3573-3582. [CrossRef]

48. Rawolle, M.; Sarkar, K.; Niedermeier, M.A.; Schindler, M.; Lellig, P.; Gutmann, J.S.; Moulin, J.F.; Haese-Seiller, M.; Wochnik, A.S.; Scheu, C.; et al. Infiltration of polymer hole-conductor into mesoporous titania structures for solid-state dye-sensitized solar cells. ACS Appl. Mater. Interfaces 2013, 5, 719-729. [CrossRef] [PubMed]

49. We, J.H.; Kim, S.J.; Cho, B.J. Hybrid composite of screen-printed inorganic thermoelectric film and organic conducting polymer for flexible thermoelectric power generator. Energy 2014, 73, 506-512. [CrossRef]

50. Cao, H.; Zhou, X.; Zhang, Y.; Chen, L.; Liu, Z. Microspherical polyaniline/graphene nanocomposites for high performance supercapacitors. J. Power Sources 2013, 243, 715-720. [CrossRef]

51. Bahloul, A.; Nessark, B.; Briot, E.; Groult, H.; Mauger, A.; Zaghib, K.; Julien, C.M. Polypyrrole-covered $\mathrm{MnO}_{2}$ as electrode material for supercapacitor. J. Power Sources 2013, 240, 267-272. [CrossRef]

52. Li, Z.F.; Zhang, H.; Liu, Q.; Sun, L.; Stanciu, L.; Xie, J. Fabrication of high-surface-area graphene/polyaniline nanocomposites and their application in supercapacitors. ACS Appl. Mater. Interfaces 2013, 5, 2685-2691. [CrossRef] [PubMed]

53. Liu, Y.; Lu, N.; Poyraz, S.; Wang, X.; Yu, Y.; Scott, J.; Smith, J.; Kim, M.J.; Zhang, X. One-pot formation of multifunctional Pt-conducting polymer intercalated nanostructures. Nanoscale 2013, 5, 3872-3879. [CrossRef] [PubMed] 
54. Zhou, H.; Han, G.; Chang, Y.; Fu, D.; Xiao, Y. Highly stable multi-wall carbon nanotubes@poly(3,4-ethylenedioxythiophene)/poly(styrene sulfonate) core-shell composites with three-dimensional porous nano-network for electrochemical capacitors. J. Power Sources 2015, 274, 229-236. [CrossRef]

55. Feng, Z.L.; Yao, Y.Y.; Xu, J.K.; Zhang, L.; Wang, Z.F.; Wen, Y.P. One-step co-electrodeposition of graphene oxide doped poly(hydroxymethylated-3,4-ethylenedioxythiophene) film and its electrochemical studies of indole-3-acetic acid. Chin. Chem. Lett. 2014, 25, 511-516. [CrossRef]

56. Xia, X.; Chao, D.; Qi, X.; Xiong, Q.; Zhang, Y.; Tu, J.; Zhang, H.; Fan, H.J. Controllable growth of conducting polymers shell for constructing high-quality organic/inorganic core/shell nanostructures and their optical-electrochemical properties. Nano Lett. 2013, 13, 4562-4568. [CrossRef] [PubMed]

57. Singh, K.; Ohlan, A.; Pham, V.H.; Balasubramaniyan, R.; Varshney, S.; Jang, J.; Hur, S.H.; Choi, W.M.; Kumar, M.; Dhawan, S.K.; et al. Nanostructured graphene $/ \mathrm{Fe}_{3} \mathrm{O}_{4}$ incorporated polyaniline as a high performance shield against electromagnetic pollution. Nanoscale 2013, 5, 2411-2420. [CrossRef] [PubMed]

58. Huang, Y.; Su, N.; Zhang, X.; Zhao, J.; Li, H.; Liu, X.; Zhang, H. Controllable synthesis and characterization of poly(aniline-co-pyrrole) using anionic spherical polyelectrolyte brushes as dopant and template. Polym. Compos. 2014, 35, 1858-1863. [CrossRef]

59. Zhang, X.; Huang, Y.; Huang, X.; Huang, C. Synthesis and characterization of polypyrrole using $\mathrm{TiO}_{2}$ nanotube@poly(sodium styrene sulfonate) as dopant and template. Polym. Polym. Compos. 2014, 37, 462-467. [CrossRef]

60. Komiyama, H.; Komura, M.; Akimoto, Y.; Kamata, K.; Iyoda, T. Longitudinal and lateral integration of conducting polymer nanowire arrays via block-copolymer-templated electropolymerization. Chem. Mater. 2015, 27, 4972-4982. [CrossRef]

61. Choi, W.M. Simple and rapid fabrication of large-area 2D colloidal crystals for nanopatterning of conducting polymers. Microelectron. Eng. 2013, 110, 1-5. [CrossRef]

62. Tiu, B.D.B.; Pernites, R.B.; Foster, E.L.; Advincula, R.C. Conducting polymer-gold co-patterned surfaces via nanosphere lithography. J. Colloid Interface Sci. 2015, 459, 86-96. [CrossRef] [PubMed]

63. Cernat, A.; le Goff, A.; Holzinger, M.; Sandulescu, R.; Cosnier, S. Micro- to nanostructured poly(pyrrole-nitrilotriacetic acid) films via nanosphere templates: Applications to 3D enzyme attachment by affinity interactions. Anal. Bioanal. Chem. 2014, 406, 1141-1147. [CrossRef] [PubMed]

64. Atobe, M.; Yoshida, N.; Sakamoto, K.; Sugino, K.; Fuchigami, T. Preparation of highly aligned arrays of conducting polymer nanowires using templated electropolymerization in supercritical fluids. Electrochim. Acta 2013, 87, 409-415. [CrossRef]

65. Sakamoto, K.; Nakabayashi, K.; Fuchigami, T.; Atobe, M. Electrochemical and photoelectrochemical behaviors of polythiophene nanowires prepared by templated electrodeposition in supercritical fluids. Electrochem. Soc. Japan 2013, 81, 328-330. [CrossRef]

66. Kang, M.; Lee, J.E.; Shim, H.W.; Jeong, M.S.; Im, W.B.; Yoon, H. Intrinsically conductive polymer binders for electrochemical capacitor application. RSC Adv. 2014, 4, 27939-27945. [CrossRef]

67. Ahn, K.J.; Lee, Y.; Choi, H.; Kim, M.S.; Im, K.; Noh, S.; Yoon, H. Surfactant-templated synthesis of polypyrrole nanocages as redox mediators for efficient energy storage. Sci. Rep. 2015, 5, 14097. [CrossRef] [PubMed]

68. Devaki, S.J.; Sadanandhan, N.K.; Sasi, R.; Adler, H.J.P.; Pich, A. Water dispersible electrically conductive poly(3,4-ethylenedioxythiophene) nanospindles by liquid crystalline template assisted polymerization. J. Mater. Chem. C 2014, 2, 6991-7000. [CrossRef]

69. Sadanandhan, N.K.; Devaki, S.J.; Narayanan, R.K.; Cheriyathuchenaaramvalli, M. Electrochemically patterned transducer with anisotropic PEDOT through liquid crystalline template polymerization. ACS Appl. Mater. Interfaces 2015, 7, 18028-18037. [CrossRef] [PubMed]

70. Yang, L.; Zhang, Z.; Nie, G.; Wang, C.; Lu, X. Fabrication of conducting polymer/noble metal composite nanorings and their enhanced catalytic properties. J. Mater. Chem. A 2014, 3, 83-86. [CrossRef]

71. Li, Y.; Jiang, Y.; Hu, S.; Zhang, X.; Zhai, J.; Han, H.; Xiao, D.; Liu, P. Control of morphology and electromagnetic properties of polypyrrole synthesized by the template method. High Perform. Polym. 2015, 28, 255-260. [CrossRef]

72. MacNeill, C.M.; Graham, E.G.; Levi-Polyachenko, N.H. Soft template synthesis of donor-acceptor conjugated polymer nanoparticles: Structural effects, stability, and photothermal studies. J. Polym. Sci. A Polym. Chem. 2014, 52, 1622-1632. [CrossRef] 
73. Sharma, M.; Waterhouse, G.I.N.; Loader, S.W.C.; Garg, S.; Svirskis, D. High surface area polypyrrole scaffolds for tunable drug delivery. Int. J. Pharm. 2013, 443, 163-168. [CrossRef] [PubMed]

74. Rivero, O.; Huerta, F.; Montilla, F.; Sanchis, C.; Morallón, E. Electrocatalytic oxidation of ascorbic acid on mesostructured $\mathrm{SiO}_{2}$-conducting polymer composites. Eur. Polym. J. 2015, 69, 201-207. [CrossRef]

75. Samu, G.F.; Visy, C.; Rajeshwar, K.; Sarker, S.; Subramanian, V.R.; Janáky, C. Photoelectrochemical infiltration of a conducting polymer (PEDOT) into metal-chalcogenide decorated $\mathrm{TiO}_{2}$ nanotube arrays. Electrochim. Acta 2015, 151, 467-476. [CrossRef]

76. Sukchol, K.; Thongyai, S.; Praserthdam, P.; Sotzing, G.A. Effects of the addition of anionic surfactant during template polymerization of conducting polymers containing PEDOT with sulfonated poly(imide) and poly(styrene sulfonate) as templates for nano-thin film applications. Synth. Met. 2013, 179, 10-17. [CrossRef]

77. Liao, J.; Wu, S.; Yin, Z.; Huang, S.; Ning, C.; Tan, G.; Chu, P.K. Surface-dependent self-assembly of conducting polypyrrole nanotube arrays in template-free electrochemical polymerization. ACS Appl. Mater. Interfaces 2014, 6, 10946-10951. [CrossRef] [PubMed]

78. Caballero, D.; Fumagalli, L.; Teixidor, F.; Samitier, J.; Errachid, A. Directing polypyrrole growth by chemical micropatterns: A study of high-throughput well-ordered arrays of conductive 3D microrings. Sens. Actuators B Chem. 2013, 177, 1003-1009. [CrossRef]

79. Kong, S.; Fontaine, O.; Roche, J.; Bouffier, L.; Kuhn, A.; Zigah, D. Electropolymerization of polypyrrole by bipolar electrochemistry in an ionic liquid. Langmuir 2014, 30, 2973-2976. [CrossRef] [PubMed]

80. Kuwahara, T.; Sato, K.; Kondo, M.; Shimomura, M. Targeted deposition of a conducting polymer based on bipolar electrochemistry. Synth. Met. 2014, 198, 274-276. [CrossRef]

81. Junker, K.; Zandomeneghi, G.; Schuler, L.D.; Kissner, R.; Walde, P. Enzymatic polymerization of pyrrole with Trametes versicolor laccase and dioxygen in the presence of vesicles formed from AOT (sodium bis-(2-ethylhexyl) sulfosuccinate) as templates. Synth. Met. 2015, 200, 123-134. [CrossRef]

82. Li, Y.; Zhang, X.; Wang, D.; He, F.; Ni, C.; Chi, L. Fabricating sub-100nm conducting polymer nanowires by edge nanoimprint lithography. J. Colloid Interface Sci. 2015, 458, 300-304. [CrossRef] [PubMed]

83. Meier, C.; Lifincev, I.; Welland, M.E. Conducting core-shell nanowires by amyloid nanofiber templated polymerization. Biomacromolecules 2015, 16, 558-563. [CrossRef] [PubMed]

84. Wang, Z.G.; Liu, Q.; Ding, B. Shape-controlled nanofabrication of conducting polymer on planar DNA templates. Chem. Mater. 2014, 26, 3364-3367. [CrossRef]

85. Miao, Y.E.; Fan, W.; Chen, D.; Liu, T.X. High-performance supercapacitors based on hollow polyaniline nanofibers by electrospinning. ACS Appl. Mater. Interfaces 2013, 5, 4423-4428. [CrossRef] [PubMed]

86. Kim, N.J.; Kwon, J.H.; Kim, M. Highly oriented self-assembly of conducting polymer chains: Extended-chain crystallization during long-range polymerization. J. Phys. Chem. C 2013, 117, 15402-15408. [CrossRef]

87. Li, J.; Yoon, S.J.; Hsieh, B.Y.; Tai, W.; O’Donnell, M.; Gao, X. Stably doped conducting polymer nanoshells by surface initiated polymerization. Nano Lett. 2015, 15, 8217-8222. [CrossRef] [PubMed]

88. Yang, W.; Gao, Z.; Song, N.; Zhang, Y.; Yang, Y.; Wang, J. Synthesis of hollow polyaniline nano-capsules and their supercapacitor application. J. Power Sources 2014, 272, 915-921. [CrossRef]

89. Wannapob, R.; Vagin, M.Y.; Jeerapan, I.; Mak, W.C. Pure nanoscale morphology effect enhancing the energy storage characteristics of processable hierarchical polypyrrole. Langmuir 2015, 31, 11904-11913. [CrossRef] [PubMed]

90. Bai, Y.; Xu, Y.; Wang, J.; Gao, M.; Wang, J. Interface effect on the electropolymerized polypyrrole films with hollow micro/nanohorn arrays. ACS Appl. Mater. Interfaces 2014, 6, 4693-4704. [CrossRef] [PubMed]

91. Nguyen, V.Q.; Schaming, D.; Martin, P.; Lacroix, J.C. Highly resolved nanostructured PEDOT on large areas by nanosphere lithography and electrodeposition. ACS Appl. Mater. Interfaces 2015, 7, 21673-21681. [CrossRef] [PubMed]

92. Ho, D.; Zou, J.; Chen, X.; Munshi, A.; Smith, N.M.; Agarwal, V.; Hodgetts, S.I.; Plant, G.W.; Bakker, A.J.; Harvey, A.R.; Luzinov, I.; Iyer, K.S. Hierarchical patterning of multifunctional conducting polymer nanoparticles as a bionic platform for topographic contact guidance. ACS Nano 2015, 9, 1767-1774. [CrossRef] [PubMed]

93. Coletta, C.; Cui, Z.; Archirel, P.; Pernot, P.; Marignier, J.L.; Remita, S. Electron-induced growth mechanism of conducting polymers: A coupled experimental and computational investigation. J. Phys. Chem. B 2015, 119, 5282-5298. [CrossRef] [PubMed] 
94. Park, H.W.; Kim, T.; Huh, J.; Kang, M.; Lee, J.E.; Yoon, H. Anisotropic growth control of polyaniline nanostructures and their morphology-dependent electrochemical characteristics. ACS Nano 2012, 6, 7624-7633. [CrossRef] [PubMed]

95. Hong, J.Y.; Yoon, H.; Jang, J. Kinetic study of the formation of polypyrrole nanoparticles in water-soluble polymer/metal cation systems: A light-scattering analysis. Small 2010, 6, 679-686. [CrossRef] [PubMed]

96. Xia, Z.; Wang, S.; Jiang, L.; Sun, H.; Sun, G. Controllable synthesis of vertically aligned polypyrrole nanowires as advanced electrode support for fuel cells. J. Power Sources 2014, 256, 125-132. [CrossRef]

97. Xu, H.; Li, X.; Wang, G. Polyaniline nanofibers with a high specific surface area and an improved pore structure for supercapacitors. J. Power Sources 2015, 294, 16-21. [CrossRef]

98. Shen, J.; Wei, M.; Busnaina, A.; Barry, C.; Mead, J. Directed assembly of conducting polymers on sub-micron templates by electrical fields. Mater. Sci. Eng. B 2013, 178, 190-201. [CrossRef]

99. Bhandari, S.; Khastgir, D. Template-free solid state synthesis of ultra-long hairy polyaniline nanowire supercapacitor. Mater. Lett. 2014, 135, 202-205. [CrossRef]

100. Kwon, O.S.; Park, S.J.; Park, H.W.; Kim, T.; Kang, M.; Jang, J.; Yoon, H. Kinetically controlled formation of multidimensional poly(3,4-ethylenedioxythiophene) nanostructures in vapor-deposition polymerization. Chem. Mater. 2012, 24, 4088-4092. [CrossRef]

101. Kwon, O.S.; Park, S.J.; Yoon, H.; Jang, J. Highly sensitive and selective chemiresistive sensors based on multidimensional polypyrrole nanotubes. Chem. Commun. 2012, 48, 10526-10528. [CrossRef] [PubMed]

102. Chen, L.; Jin, J.; Shu, X.; Xia, J. Solid state synthesis of poly(3,4-ethylenedioxythiophene) as counter electrode for dye-sensitized solar cell. J. Power Sources 2014, 248, 1234-1240. [CrossRef]

103. Zhao, H.; Zhu, B.; Luo, S.C.; Lin, H.A.; Nakao, A.; Yamashita, Y.; Yu, H.H. Controlled protein absorption and cell adhesion on polymer-brush-grafted poly(3,4-ethylenedioxythiophene) films. ACS Appl. Mater. Interfaces 2013, 5, 4536-4543. [CrossRef] [PubMed]

104. Li, X.; Yang, L.; Lei, Y.; Gu, L.; Xiao, D. Microwave-assisted chemical-vapor-induced in situ polymerization of polyaniline nanofibers on graphite electrode for high-performance supercapacitor. ACS Appl. Mater. Interfaces 2014, 6, 19978-19989. [CrossRef] [PubMed]

105. Lee, J.E.; Lee, Y.; Ahn, K.J.; Huh, J.; Shim, H.W.; Sampath, G.; Im, W. Bin; Huh, Y.; Yoon, H. Role of co-vapors in vapor deposition polymerization. Sci. Rep. 2015, 5, 8420. [CrossRef] [PubMed]

106. Jiang, S.; Sun, Y.; Cui, X.; Huang, X.; He, Y.; Ji, S.; Shi, W.; Ge, D. Enhanced drug loading capacity of polypyrrole nanowire network for controlled drug release. Synth. Met. 2013, 163, 19-23. [CrossRef]

107. Wu, D.; Zhang, J.; Dong, W.; Chen, H.; Huang, X.; Sun, B.; Chen, L. Temperature dependent conductivity of vapor-phase polymerized PEDOT films. Synth. Met. 2013, 176, 86-91. [CrossRef]

108. Cho, B.; Park, K.S.; Baek, J.; Oh, H.S.; Koo Lee, Y.E.; Sung, M.M. Single-crystal poly(3,4-ethylenedioxythiophene) nanowires with ultrahigh conductivity. Nano Lett. 2014, 14, 3321-3327. [CrossRef] [PubMed]

109. Vucaj, N.; Quinn, M.; Baechler, C.; Notley, S.M.; Cottis, P.; Hojati-Talemi, P.; Fabretto, M.V.; Wallace, G.G.; Evans, D.R. Vapour phase synthesis of conducting polymer nanocomposites incorporating 2D nanoparticles. Chem. Mater. 2014, 26, 4207-4213. [CrossRef]

110. D’Arcy, J.M.; El-Kady, M.F.; Khine, P.P.; Zhang, L.; Lee, S.H.; Davis, N.R.; Liu, D.S.; Yeung, M.T.; Kim, S.Y.; Turner, C.L.; et al. Vapor-phase polymerization of nanofibrillar poly(3,4-ethylenedioxythiophene) for supercapacitors. ACS Nano 2014, 8, 1500-1510. [CrossRef] [PubMed]

111. Yang, Y.; Yuan, W.; Li, S.; Yang, X.; Xu, J.; Jiang, Y. Manganese dioxide nanoparticle enrichment in porous conducting polymer as high performance supercapacitor electrode materials. Electrochim. Acta 2015, 165, 323-329. [CrossRef]

112. Ji, J.; Zhang, X.; Liu, J.; Peng, L.; Chen, C.; Huang, Z.; Li, L.; Yu, X.; Shang, S. Assembly of polypyrrole nanotube@ $\mathrm{MnO}_{2}$ composites with an improved electrochemical capacitance. Mater. Sci. Eng. B 2015, 198, 51-56. [CrossRef]

113. Ren, L.; Zhang, G.; Wang, J.; Kang, L.; Lei, Z.; Liu, Z.; Liu, Z.; Hao, Z.; Liu, Z. Adsorption-template preparation of polyanilines with different morphologies and their capacitance. Electrochim. Acta 2014, 145, 99-108. [CrossRef]

114. Chen, W.; Rakhi, R.B.; Alshareef, H.N. Morphology-dependent enhancement of the pseudocapacitance of template-guided tunable polyaniline nanostructures. J. Phys. Chem. C 2013, 117, 15009-15019. [CrossRef] 
115. Chen, W.; Rakhi, R.B.; Alshareef, H.N. Facile synthesis of polyaniline nanotubes using reactive oxide templates for high energy density pseudocapacitors. J. Mater. Chem. A 2013, 1, 3315-3324. [CrossRef]

116. Bogdanović, U.; Pašti, I.; Ćirić-Marjanović, G.; Mitrić, M.; Ahrenkiel, S.P.; Vodnik, V. Interfacial synthesis of gold-polyaniline nanocomposite and its electrocatalytic application. ACS Appl. Mater. Interfaces 2015, 7, 28393-28403. [CrossRef] [PubMed]

117. Bogdanović, U.; Vodnik, V.; Mitrić, M.; Dimitrijević, S.; Škapin, S.D.; Žunič, V.; Budimir, M.; Stoiljković, M. Nanomaterial with high antimicrobial efficacy—copper/polyaniline nanocomposite. ACS Appl. Mater. Interfaces 2015, 7, 1955-1966. [CrossRef] [PubMed]

118. Cai, G.; Tu, J.; Zhou, D.; Zhang, J.; Xiong, Q.; Zhao, X. Multicolor electrochromic film based on TiO $\mathrm{T}_{2}$ polyaniline core/shell nanorod array. J. Phys. Chem. B 2013, 117, 15967-15975. [CrossRef]

119. Gulce, H.; Eskizeybek, V.; Haspulat, B.; Sari, F.; Gulce, A.; Avci, A. Preparation of a new polyaniline/CdO nanocomposite and investigation of its photocatalytic activity: comparative study under UV light and natural sunlight irradiation. Ind. Eng. Chem. Res. 2013, 52, 10924-10934. [CrossRef]

120. Ren, L.; Zhang, G.; Yan, Z.; Kang, L.; Xu, H.; Shi, F.; Lei, Z.; Liu, Z.H. Three-dimensional tubular MoS $2 /$ PANI hybrid electrode for high rate performance supercapacitor. ACS Appl. Mater. Interfaces 2015, 7, 28294-28302. [CrossRef] [PubMed]

121. Xue, T.; Wang, X.; Kwak, S.K.; Lee, J. Synthesis of mesoporous polyaniline (PANI)-Se $0.5 \mathrm{Te}_{0.5}$ dual-layer film from lyotropic liquid crystalline template. Ind. Eng. Chem. Res. 2013, 52, 5072-5078. [CrossRef]

122. Khilari, S.; Pandit, S.; Varanasi, J.L.; Das, D.; Pradhan, D. Bifunctional manganese ferrite/polyaniline hybrid as electrode material for enhanced energy recovery in microbial fuel cell. ACS Appl. Mater. Interfaces 2015, 7, 20657-20666. [CrossRef] [PubMed]

123. He, W.; Li, G.; Zhang, S.; Wei, Y.; Wang, J.; Li, Q. Polypyrrole/silver coaxial nanowire independent stress sensing and stress-triggered joule heating. ACS Nano 2015, 9, 4244-4251. [CrossRef] [PubMed]

124. Hnida, K.E.; Socha, R.P.; Sulka, G.D. Polypyrrole-silver composite nanowire arrays by cathodic co-deposition and their electrochemical properties. J. Phys. Chem. C 2013, 117, 19382-19392. [CrossRef]

125. Huang, J.; Yang, Z.; Yang, B.; Wang, R.; Wang, T. Ultrasound assisted polymerization for synthesis of $\mathrm{ZnO} /$ Polypyrrole composites for zinc/nickel rechargeable battery. J. Power Sources 2014, 271, 143-151. [CrossRef]

126. Yin, Z.; Fan, W.; Ding, Y.; Li, J.; Guan, L.; Zheng, Q. Shell structure control of PPy-modified CuO composite nanoleaves for lithium batteries with improved cyclic performance. ACS Sustain. Chem. Eng. 2015, 3, 507-517. [CrossRef]

127. Zhou, C.; Zhang, Y.; Li, Y.; Liu, J. Construction of high-capacitance 3D CoO@polypyrrole nanowire array electrode for aqueous asymmetric supercapacitor. Nano Lett. 2013, 13, 2078-2085. [CrossRef] [PubMed]

128. Ma, G.; Peng, H.; Mu, J.; Huang, H.; Zhou, X.; Lei, Z. In situ intercalative polymerization of pyrrole in graphene analogue of $\mathrm{MoS}_{2}$ as advanced electrode material in supercapacitor. J. Power Sources 2013, 229, 72-78. [CrossRef]

129. Ngaboyamahina, E.; Debiemme-Chouvy, C.; Pailleret, A.; Sutter, E.M.M. Electrodeposition of polypyrrole in $\mathrm{TiO}_{2}$ nanotube arrays by pulsed-light and pulsed-potential methods. J. Phys. Chem. C 2014, 118, 26341-26350. [CrossRef]

130. Liu, L.L.; Wang, X.J.; Zhu, Y.S.; Hu, C.L.; Wu, Y.P.; Holze, R. Polypyrrole-coated $\mathrm{LiV}_{3} \mathrm{O}_{8}$-nanocomposites with good electrochemical performance as anode material for aqueous rechargeable lithium batteries. J. Power Sources 2013, 224, 290-294. [CrossRef]

131. Zhong, X.B.; Wang, H.Y.; Yang, Z.Z.; Jin, B.; Jiang, Q.C. Facile synthesis of mesoporous $\mathrm{ZnCO}_{2} \mathrm{O}_{4}$ coated with polypyrrole as an anode material for lithium-ion batteries. J. Power Sources 2015, 296, 298-304. [CrossRef]

132. Guo, C.X.; Sun, K.; Ouyang, J.; Lu, X. Layered $\mathrm{V}_{2} \mathrm{O}_{5} /$ PEDOT nanowires and ultrathin nanobelts fabricated with a silk reelinglike process. Chem. Mater. 2015, 27, 5813-5819. [CrossRef]

133. Taccola, S.; Greco, F.; Zucca, A.; Innocenti, C.; De Julián Fernández, C.; Campo, G.; Sangregorio, C.; Mazzolai, B.; Mattoli, V. Characterization of free-standing PEDOT:PSS/iron oxide nanoparticle composite thin films and application as conformable humidity sensors. ACS Appl. Mater. Interfaces 2013, 5, 6324-6332. [CrossRef] [PubMed]

134. Williams, P.E.; Jones, S.T.; Walsh, Z.; Appel, E.A.; Abo-Hamed, E.K.; Scherman, O.A. Synthesis of conducting polymer-metal nanoparticle hybrids exploiting RAFT polymerization. ACS Macro Lett. 2015, 4, 255-259. [CrossRef] 
135. Attia, M.F.; Azib, T.; Salmi, Z.; Singh, A.; Decorse, P.; Battaglini, N.; Lecoq, H.; Omastová, M.; Higazy, A. A.; Elshafei, A.M.; et al. One-step UV-induced modification of cellulose fabrics by polypyrrole/silver nanocomposite films. J. Colloid Interface Sci. 2013, 393, 130-137. [CrossRef] [PubMed]

136. Singh, A.; Salmi, Z.; Jha, P.; Joshi, N.; Kumar, A.; Decorse, P.; Lecoq, H.; Lau-Truong, S.; Aswal, D.K.; Gupta, S.K.; Chehimi, M.M. One step synthesis of highly ordered free standing flexible polypyrrole-silver nanocomposite films at air-water interface by photopolymerization. RSC Adv. 2013, 3, 13329-13336. [CrossRef]

137. Heydarnezhad, H.R.; Pourabbas, B. One-step synthesis of conductive ceria/polypyrrole nanocomposite particles via photo-induced polymerization method. J. Mater. Sci. Mater. Electron. 2013, 24, 4378-4385. [CrossRef]

138. Asmussen, S.; Arenas, G.; Vallo, C. Photopolymerization of pyrrole/methacrylate mixtures using $\alpha$-cleavage type photoinitiators in combination with iodonium salt. Synth. Met. 2015, 209, 304-312. [CrossRef]

139. Jlassi, K.; Singh, A.; Aswal, D.K.; Losno, R.; Benna-Zayani, M.; Chehimi, M.M. Novel, ternary clay/polypyrrole/silver hybrid materials through in situ photopolymerization. Colloids Surfaces A Physicochem. Eng. Asp. 2013, 439, 193-199. [CrossRef]

140. Zhang, J.; Yang, L.; Shen, Y.; Park, B.W.; Hao, Y.; Johansson, E.M.J.; Boschloo, G.; Kloo, L.; Gabrielsson, E.; Sun, L.; et al. Poly(3,4-ethylenedioxythiophene) hole-transporting material generated by photoelectrochemical polymerization in aqueous and organic medium for all-solid-state dye-sensitized solar cells. J. Phys. Chem. C 2014, 118, 16591-16601. [CrossRef]

141. Yang, L.; Zhang, J.; Shen, Y.; Park, B.W.; Bi, D.; Häggman, L.; Johansson, E.M.J.; Boschloo, G.; Hagfeldt, A.; Vlachopoulos, N.; et al. New approach for preparation of efficient solid-state dye-sensitized solar cells by photoelectrochemical polymerization in aqueous micellar solution. J. Phys. Chem. Lett. 2013, 4, 4026-4031. [CrossRef]

142. Park, B.W.; Yang, L.; Johansson, E.M.J.; Vlachopoulos, N.; Chams, A.; Perruchot, C.; Jouini, M.; Boschloo, G.; Hagfeldt, A. Neutral, polaron, and bipolaron states in PEDOT prepared by photoelectrochemical polymerization and the effect on charge generation mechanism in the solid-state dye-sensitized solar cell. J. Phys. Chem. C 2013, 117, 22484-22491. [CrossRef]

143. Li, J.; Xie, H.; Li, Y. Fabrication of graphene oxide/polypyrrole nanowire composite for high performance supercapacitor electrodes. J. Power Sources 2013, 241, 388-395. [CrossRef]

144. Song, Y.; Xu, J.L.; Liu, X.X. Electrochemical anchoring of dual doping polypyrrole on graphene sheets partially exfoliated from graphite foil for high-performance supercapacitor electrode. J. Power Sources 2014, 249, 48-58. [CrossRef]

145. Zhu, Y.; Shi, K.; Zhitomirsky, I. Polypyrrole coated carbon nanotubes for supercapacitor devices with enhanced electrochemical performance. J. Power Sources 2014, 268, 233-239. [CrossRef]

146. Wang, M.; Jamal, R.; Wang, Y.; Yang, L.; Liu, F.; Abdiryim, T. Functionalization of graphene oxide and its composite with poly(3,4-ethylenedioxythiophene) as electrode material for supercapacitors. Nanoscale Res. Lett. 2015, 10. [CrossRef] [PubMed]

147. Lee, Y.; Choi, H.; Kim, M.S.; Noh, S.; Ahn, K.J.; Im, K.; Kwon, O.S.; Yoon, H. Nanoparticle-mediated physical exfoliation of aqueous-phase graphene for fabrication of three-dimensionally structured hybrid electrodes. Sci. Rep. 2016, 6. [CrossRef] [PubMed]

148. He, B.; Tang, Q.; Wang, M.; Ma, C.; Yuan, S. Complexation of polyaniline and graphene for efficient counter electrodes in dye-sensitized solar cells: Enhanced charge transfer ability. J. Power Sources 2014, 256, 8-13. [CrossRef]

149. Wang, Q.; Yan, J.; Fan, Z.; Wei, T.; Zhang, M.; Jing, X. Mesoporous polyaniline film on ultra-thin graphene sheets for high performance supercapacitors. J. Power Sources 2014, 247, 197-203. [CrossRef]

150. Gao, S.; Zang, P.; Dang, L.; Xu, H.; Shi, F.; Liu, Z.; Lei, Z. Extraordinarily high-rate capability of polyaniline nanorod arrays on graphene nanomesh. J. Power Sources 2016, 304, 111-118. [CrossRef]

151. Wang, Y.S.; Li, S.M.; Hsiao, S.T.; Liao, W.H.; Yang, S.Y.; Tien, H.W.; Ma, C.C.M.; Hu, C.C. Thickness-self-controlled synthesis of porous transparent polyaniline-reduced graphene oxide composites towards advanced bifacial dye-sensitized solar cells. J. Power Sources 2014, 260, 326-337. [CrossRef]

152. Yang, C.; Zhang, L.; Hu, N.; Yang, Z.; Wei, H.; Zhang, Y. Reduced graphene oxide/polypyrrole nanotube papers for fl exible all-solid-state supercapacitors with excellent rate capability and high energy density. J. Power Sources 2016, 302, 39-45. [CrossRef] 
153. Yang, X.; Liu, A.; Zhao, Y.; Lu, H.; Zhang, Y.; Wei, W.; Li, Y.; Liu, S. Three-dimensional macroporous polypyrrole-derived graphene electrode prepared by the hydrogen bubble dynamic template for supercapacitors and metal-free catalysts. ACS Appl. Mater. Interfaces 2015, 7, 23731-23740. [CrossRef] [PubMed]

154. De Oliveira, H.P.; Sydlik, S.A.; Swager, T.M. Supercapacitors from free-standing polypyrrole/graphene nanocomposites. J. Phys. Chem. C 2013, 117, 10270-10276. [CrossRef]

155. Kumar, G.G.; Kirubaharan, C.J.; Udhayakumar, S.; Ramachandran, K.; Karthikeyan, C.; Renganathan, R.; Nahm, K.S. Synthesis, structural, and morphological characterizations of reduced graphene oxide-supported polypyrrole anode catalysts for improved microbial fuel cell performances. ACS Sustain. Chem. Eng. 2014, 2, 2283-2290. [CrossRef]

156. Li, S.; Shu, K.; Zhao, C.; Wang, C.; Guo, Z.; Wallace, G.; Liu, H.K. One-step synthesis of graphene/polypyrrole nanofiber composites as cathode material for a biocompatible zinc/polymer battery. ACS Appl. Mater. Interfaces 2014, 6, 16679-16686. [CrossRef] [PubMed]

157. Bora, C.; Sharma, J.; Dolui, S. Polypyrrole/sulfonated graphene composite as electrode material for supercapacitor. J. Phys. Chem. C 2014, 118, 29688-29694. [CrossRef]

158. Yang, Y.; Li, S.; Yang, W.; Yuan, W.; Xu, J.; Jiang, Y. In situ polymerization deposition of porous conducting polymer on reduced graphene oxide for gas sensor. ACS Appl. Mater. Interfaces 2014, 6, 13807-13814. [CrossRef] [PubMed]

159. De Souza, V.H.R.; Oliveira, M.M.; Zarbin, A.J.G. Thin and flexible all-solid supercapacitor prepared from novel single wall carbon nanotubes/polyaniline thin films obtained in liquid-liquid interfaces. J. Power Sources 2014, 260, 34-42. [CrossRef]

160. Yameen, B.; Zydziak, N.; Weidner, S.M.; Bruns, M.; Barner-Kowollik, C. Conducting polymer/SWCNTs modular hybrid materials via Diels-Alder ligation. Macromolecules 2013, 46, 2606-2615. [CrossRef]

161. Jiang, W.; Yu, D.; Zhang, Q.; Goh, K.; Wei, L.; Yong, Y.; Jiang, R.; Wei, J.; Chen, Y. Ternary hybrids of amorphous nickel hydroxide-carbon nanotube-conducting polymer for supercapacitors with high energy density, excellent rate capability, and long cycle life. Adv. Funct. Mater. 2015, 25, 1063-1073. [CrossRef]

162. Sekkarapatti Ramasamy, M.; Nikolakapoulou, A.; Raptis, D.; Dracopoulos, V.; Paterakis, G.; Lianos, P. Reduced graphene oxide/Polypyrrole/PEDOT composite films as efficient Pt-free counter electrode for dye-sensitized solar cells. Electrochim. Acta 2015, 173, 276-281. [CrossRef]

163. Cheng, Q.; Tang, J.; Shinya, N.; Qin, L.C. Polyaniline modified graphene and carbon nanotube composite electrode for asymmetric supercapacitors of high energy density. J. Power Sources 2013, 241, 423-428. [CrossRef]

164. Cui, H.F.; Du, L.; Guo, P.B.; Zhu, B.; Luong, J.H.T. Controlled modification of carbon nanotubes and polyaniline on macroporous graphite felt for high-performance microbial fuel cell anode. J. Power Sources 2015, 283, 46-53. [CrossRef]

165. Zhou, Z.; Wu, X.F. High-performance porous electrodes for pseudosupercapacitors based on graphene-beaded carbon nanofibers surface-coated with nanostructured conducting polymers. J. Power Sources 2014, 262, 44-49. [CrossRef]

166. Moon, S.; Jung, Y.H.; Kim, D.K. Enhanced electrochemical performance of a crosslinked polyaniline-coated graphene oxide-sulfur composite for rechargeable lithium-sulfur batteries. J. Power Sources 2015, 294, 386-392. [CrossRef]

167. Pan, C.; Gu, H.; Dong, L. Synthesis and electrochemical performance of polyaniline@ $\mathrm{MnO}_{2} /$ graphene ternary composites for electrochemical supercapacitors. J. Power Sources 2016, 303, 175-181. [CrossRef]

168. Shen, J.; Yang, C.; Li, X.; Wang, G. High-performance asymmetric supercapacitor based on nanoarchitectured polyaniline/graphene/carbon nanotube and activated graphene electrodes. ACS Appl. Mater. Interfaces 2013, 5, 8467-8476. [CrossRef] [PubMed]

169. Wang, W.; Hao, Q.; Lei, W.; Xia, X.; Wang, X. Ternary nitrogen-doped graphene/nickel ferrite/polyaniline nanocomposites for high-performance supercapacitors. J. Power Sources 2014, 269, 250-259. [CrossRef]

170. Hu, T.H.; Yin, Z.S.; Guo, J.W.; Wang, C. Synthesis of Fe nanoparticles on polyaniline covered carbon nanotubes for oxygen reduction reaction. J. Power Sources 2014, 272, 661-671. [CrossRef]

171. Xiao, Y.; Wang, W.Y.; Chou, S.W.; Lin, T.W.; Lin, J.Y. In situ electropolymerization of polyaniline/cobalt sulfide decorated carbon nanotube composite catalyst toward triiodide reduction in dye-sensitized solar cells. J. Power Sources 2014, 266, 448-455. [CrossRef] 
172. Xiong, P.; Hu, C.; Fan, Y.; Zhang, W.; Zhu, J.; Wang, X. Ternary manganese ferrite/graphene/polyaniline nanostructure with enhanced electrochemical capacitance performance. J. Power Sources 2014, 266, 384-392. [CrossRef]

173. Yang, L.; Tang, Y.; Yan, D.; Liu, T.; Liu, C.; Luo, S. Polyaniline-reduced graphene oxide hybrid nanosheets with nearly vertical orientation anchoring palladium nanoparticles for highly active and stable electrocatalysis. ACS Appl. Mater. Interfaces 2015, 8, 169-176. [CrossRef] [PubMed]

174. Dhibar, S.; Das, C.K. Silver nanoparticles decorated polyaniline/multiwalled carbon nanotubes nanocomposite for high-performance supercapacitor electrode. Ind. Eng. Chem. Res. 2014, 53, 3495-3508. [CrossRef]

175. Xie, Y.; Xia, C.; Du, H.; Wang, W. Enhanced electrochemical performance of polyaniline/carbon/titanium nitride nanowire array for flexible supercapacitor. J. Power Sources 2015, 286, 561-570. [CrossRef]

176. Zhao, X.; Ahn, H.J.; Kim, K.W.; Cho, K.K.; Ahn, J.H. Polyaniline-coated mesoporous carbon/sulfur composites for advanced lithium sulfur batteries. J. Phys. Chem. C 2015, 119, 7996-8003. [CrossRef]

177. Peng, Y.J.; Wu, T.H.; Hsu, C.T.; Li, S.M.; Chen, M.G.; Hu, C.C. Electrochemical characteristics of the reduced graphene oxide/carbon nanotube/polypyrrole composites for aqueous asymmetric supercapacitors. J. Power Sources 2014, 272, 970-978. [CrossRef]

178. Zhang, Y.; Zhao, Y.; Konarov, A.; Gosselink, D.; Soboleski, H.G.; Chen, P. A novel nano-sulfur/ polypyrrole/graphene nanocomposite cathode with a dual-layered structure for lithium rechargeable batteries. J. Power Sources 2013, 241, 517-521. [CrossRef]

179. De Oliveira, A.H.P.; de Oliveira, H.P. Carbon nanotube/ polypyrrole nanofibers core-shell composites decorated with titanium dioxide nanoparticles for supercapacitor electrodes. J. Power Sources 2014, 268, 45-49. [CrossRef]

180. Lin, J.Y.; Wang, W.Y.; Chou, S.W. Flexible carbon nanotube/polypropylene composite plate decorated with poly(3,4-ethylenedioxythiophene) as efficient counter electrodes for dye-sensitized solar cells. J. Power Sources 2015, 282, 348-357. [CrossRef]

181. Wang, Y.; Chu, W.; Wang, S.; Li, Z.; Zeng, Y.; Yan, S.; Sun, Y. Simple synthesis and photoelectrochemical characterizations of polythiophene/Pd/ $\mathrm{TiO}_{2}$ composite microspheres. ACS Appl. Mater. Interfaces 2014, 6, 20197-20204. [CrossRef] [PubMed]

182. Cho, S.; Kim, M.; Jang, J. Screen-printable and flexible $\mathrm{RuO}_{2}$ nanoparticle-decorated PEDOT:PSS/graphene nanocomposite with enhanced electrical and electrochemical performances for high-capacity supercapacitor. ACS Appl. Mater. Interfaces 2015, 7, 10213-10227. [CrossRef] [PubMed]

183. Lee, B.H.; Lee, J.H.; Kahng, Y.H.; Kim, N.; Kim, Y.J.; Lee, J.; Lee, T.; Lee, K. Graphene-conducting polymer hybrid transparent electrodes for efficient organic optoelectronic devices. Adv. Funct. Mater. 2014, 24, 1847-1856. [CrossRef]

184. Park, S.J.; Song, H.S.; Kwon, O.S.; Chung, J.H.; Lee, S.H.; An, J.H.; Ahn, S.R.; Lee, J.E.; Yoon, H.; Park, T.H.; et al. Human dopamine receptor nanovesicles for gate-potential modulators in high-performance field-effect transistor biosensors. Sci. Rep. 2014, 4, 1-8. [CrossRef] [PubMed]

185. Kwon, O.S.; Park, S.J.; Lee, J.S.; Park, E.; Kim, T.; Park, H.W.; You, S.A.; Yoon, H.; Jang, J. Multidimensional conducting polymer nanotubes for ultrasensitive chemical nerve agent sensing. Nano Lett. 2012, 12, 2797-2802. [CrossRef] [PubMed]

186. Zhong, Q.; Xu, H.; Ding, H.; Bai, L.; Mu, Z.; Xie, Z.; Zhao, Y.; Gu, Z. Preparation of conducting polymer inverse opals and its application as ammonia sensor. Colloids Surfaces A Physicochem. Eng. Asp. 2013, 433, 59-63. [CrossRef]

187. Lee, J.E.; Shim, H.W.; Kwon, O.S.; Huh, Y.I.; Yoon, H. Real-time detection of metal ions using conjugated polymer composite papers. Analyst 2014, 139, 4466-4475. [CrossRef] [PubMed]

188. La Ferrara, V.; Rametta, G.; de Maria, A. AC electric field for rapid assembly of nanostructured polyaniline onto microsized gap for sensor devices. Electrophoresis 2015, 36, 1459-1465. [CrossRef] [PubMed]

189. Yoon, H.; Ko, S.; Jang, J. Field-effect-transistor sensor based on enzyme-functionalized polypyrrole nanotubes for glucose detection. J. Phys. Chem. B 2008, 112, 9992-9997. [CrossRef] [PubMed]

190. Yoon, H.; Lee, S.H.; Kwon, O.S.; Song, H.S.; Oh, E.H.; Park, T.H.; Jang, J. Polypyrrole nanotubes conjugated with human olfactory receptors: High-Performance transducers for FET-Type bioelectronic noses. Angew. Chem. 2009, 48, 2755-2758. [CrossRef] [PubMed] 
191. Yoon, H.; Jang, J. A field-effect-transistor sensor based on polypyrrole nanotubes coupled with heparin for thrombin detection. Mol. Cryst. Liq. Cryst. 2008, 491, 21-31. [CrossRef]

192. Yoon, H.; Kim, J.H.; Lee, N.; Kim, B.G.; Jang, J. A novel sensor platform based on aptamer-conjugated polypyrrole nanotubes for label-free electrochemical protein detection. ChemBioChem 2008, 9, 634-641. [CrossRef] [PubMed]

193. Kwon, O.S.; Ahn, S.R.; Park, S.J.; Song, H.S.; Lee, S.H.; Lee, J.S.; Hong, J.Y.; Lee, J.S.; You, S.A.; Yoon, H.; Park, T. H.; Jang, J. Ultrasensitive and selective recognition of peptide hormone using close-packed arrays of hPTHR-conjugated polymer nanoparticles. ACS Nano 2012, 6, 5549-5558. [CrossRef] [PubMed]

194. Chiam, Y.S.; Lim, K.S.; Harun, S.W.; Gan, S.N.; Phang, S.W. Conducting polymer coated optical microfiber sensor for alcohol detection. Sens. Actuators A Phys. 2014, 205, 58-62. [CrossRef]

195. Chen, W.; Xia, C.; Rakhi, R.B.; Alshareef, H.N. A general approach toward enhancement of pseudocapacitive performance of conducting polymers by redox-active electrolytes. J. Power Sources 2014, 267, 521-526. [CrossRef]

196. Lee, J.E.; Park, S.J.; Kwon, O.S.; Shim, H.W.; Jang, J.; Yoon, H. Systematic investigation on charge storage behaviour of multidimensional poly(3,4-ethylenedioxythiophene) nanostructures. RSC Adv. 2014, 4, 37529-37535. [CrossRef]

197. Choi, H.; Yoon, H. Nanostructured electrode materials for electrochemical capacitor applications. Nanomaterials 2015, 5, 906-936. [CrossRef]

198. Kung, C.W.; Cheng, Y.H.; Chen, H.W.; Vittal, R.; Ho, K.C. Hollow microflower arrays of PEDOT and their application for the counter electrode of a dye-sensitized solar cell. J. Mater. Chem. A 2013, 1, 10693-10702. [CrossRef]

199. Saranya, K.; Rameez, M.; Subramania, A. Developments in conducting polymer based counter electrodes for dye-sensitized solar cells-An overview. Eur. Polym. J. 2015, 66, 207-227. [CrossRef]

200. Yin, X.; Wu, F.; Fu, N.; Han, J.; Chen, D.; Xu, P.; He, M.; Lin, Y. Facile synthesis of poly(3,4-ethylenedioxythiophene) film via solid-state polymerization as high-performance Pt-free counter electrodes for plastic dye-sensitized solar cells. ACS Appl. Mater. Interfaces 2013, 5, 8423-8429. [CrossRef] [PubMed]

201. Kim, J.S.; Kim, W.J.; Cho, N.; Shukla, S.; Yoon, H.; Jang, J.; Prasad, P.N.; Kim, T.D.; Lee, K.S. Synthesis and properties of quantum dot-polypyrrole nanotube composites for photovoltaic application. J. Nanosci. Nanotechnol. 2009, 9, 6957-6961. [CrossRef] [PubMed]

202. Krukiewicz, K.; Jarosz, T.; Zak, J.K.; Lapkowski, M.; Ruszkowski, P.; Bobkiewicz-Kozlowska, T.; Bednarczyk-Cwynar, B. Advancing the delivery of anticancer drugs: Conjugated polymer/triterpenoid composite. Acta Biomater. 2015, 19, 158-165. [CrossRef] [PubMed]

203. Hong, W.Y.; Jeon, S.H.; Lee, E.S.; Cho, Y. An integrated multifunctional platform based on biotin-doped conducting polymer nanowires for cell capture, release, and electrochemical sensing. Biomaterials 2014, 35, 9573-9580. [CrossRef] [PubMed]

204. In, C.; Kim, H.; Min, B.; Choi, H. Photoinduced nonlinear mixing of terahertz dipole resonances in graphene metadevices. Adv. Mater. 2016, 28, 1495-1500. [CrossRef] [PubMed]

205. Groenendaal, L.; Jonas, F.; Freitag, D.; Pielartzik, H.; Reynolds, J.R. Poly(3,4-ethylenedioxythiophene) and its derivatives: Past, present, and future. Adv. Mater. 2000, 12, 481-494. [CrossRef]

(C) 2016 by the authors; licensee MDPI, Basel, Switzerland. This article is an open access article distributed under the terms and conditions of the Creative Commons by Attribution (CC-BY) license (http://creativecommons.org/licenses/by/4.0/). 